اثر اسيد سولفوريك، اسيد هيوميك و محلولياشى برگى نيترات يتاسيم بر كيفيت رنى گلبرى، خاصيت آنتىاكسيدانى، كاروتنوئيد و عملكرد گل در هميشهبهار (Calendula officinalis L.)

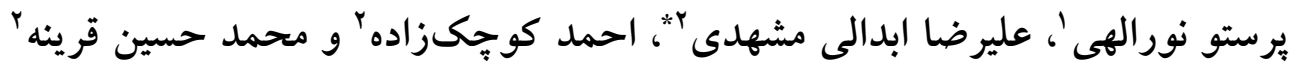
(تاريخ دريافت: س /

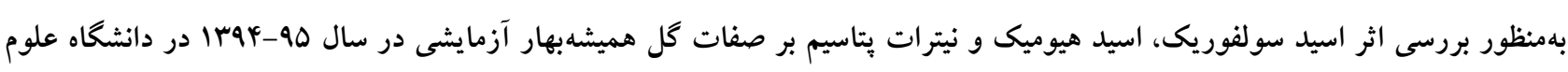

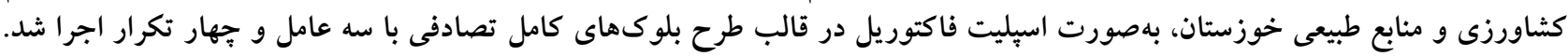
عامل نيترات يتاسيم با سه سطح (

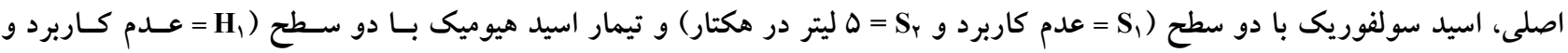


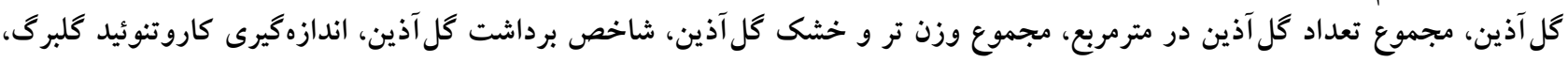

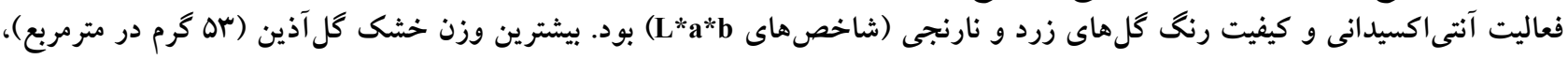

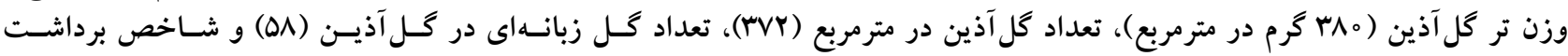

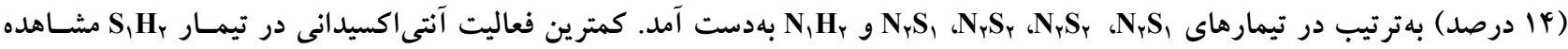

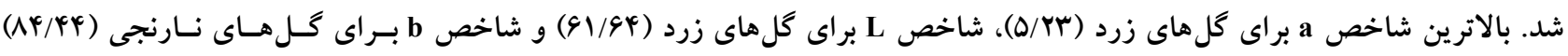

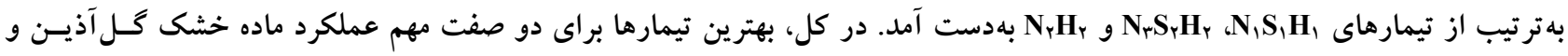
تعداد كل آذين در متر مربع بهتر تيب

وازههاى كليدى: گياه دارويى، دستخاه رنغسنج، L*a*b، كله هاى زبانهاى

ا و r. بهترتيب دانشآموخته كارشناسى ارشد و دانشيار، توليد و زنتيك گياهى، دانشكده كشاورزى، دانشخاه علوم كشاورزى و منابع طبيعى خوزستان

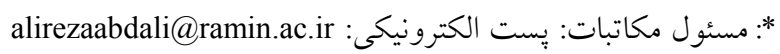


و ظرفيت فتوسنتزى بر عملكرد مؤثر هستـند. در يـك كـزارش

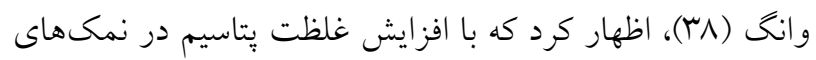

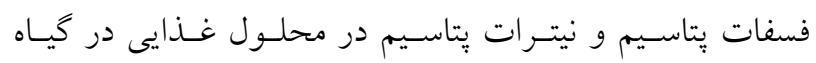

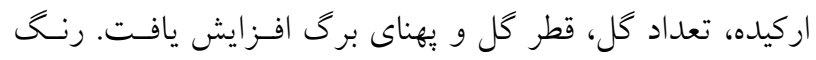

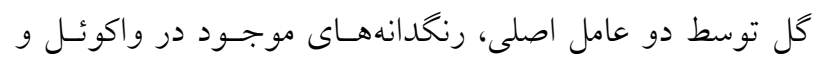

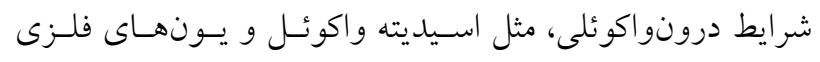

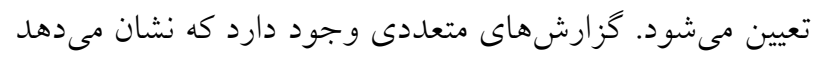

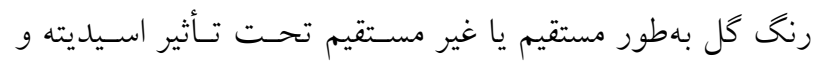

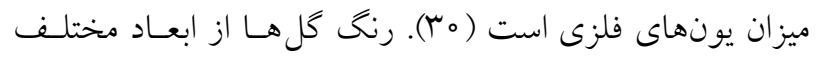

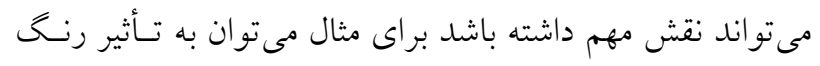

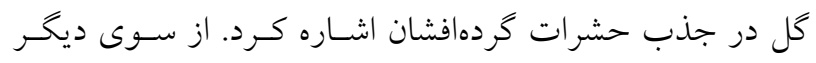

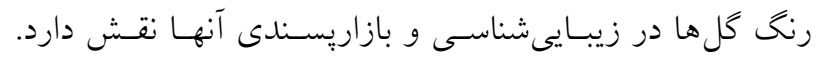

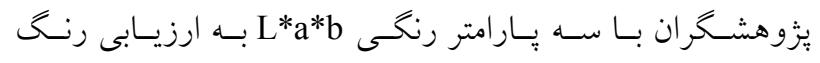

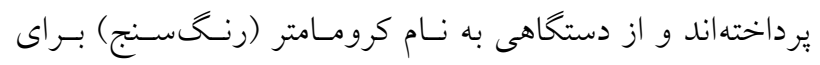

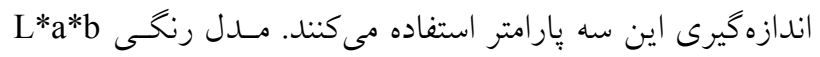

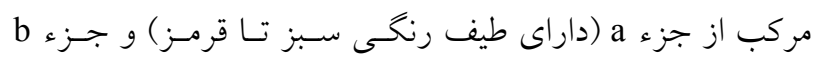

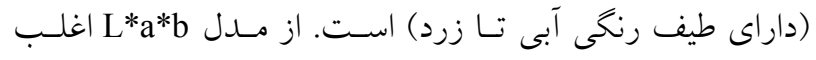
براى مطالعات تحقيقى رنخ مو اد غذايى اسفاده مسى رشـود (ra).

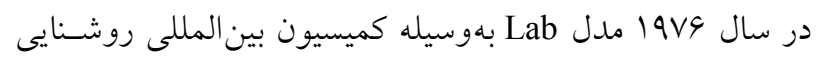

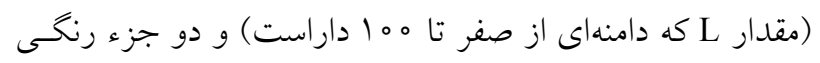

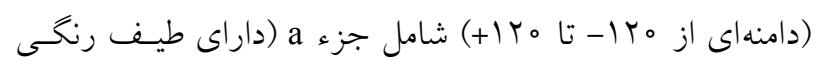

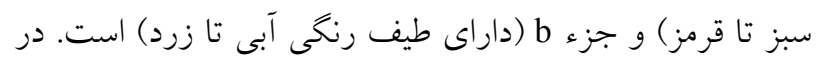

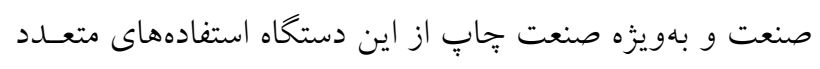

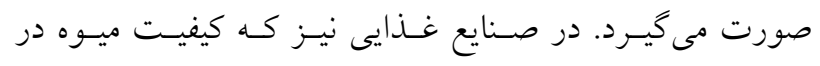

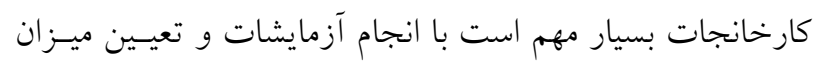

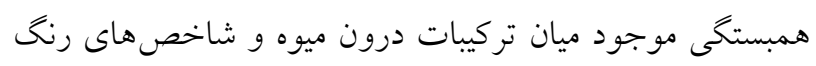

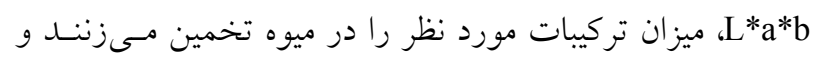

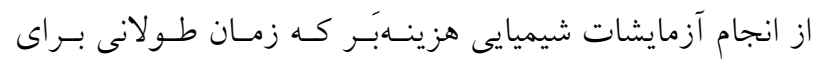

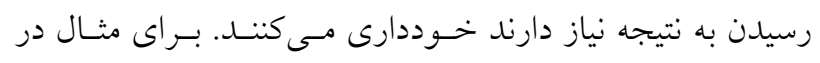

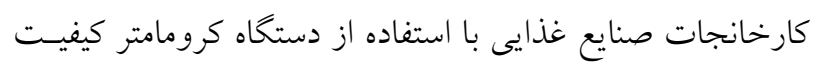

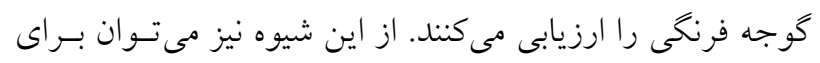

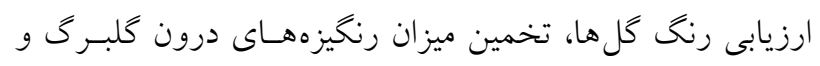
تخمين كيفيت محصـولات بـاغى و زراعى نيـز اسـتفاده كـرد.
از ديرباز قسمت هاى مختلف كيـاه زيتتى دارويسى هميشـهبهـار

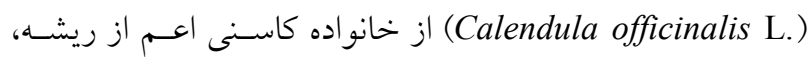
برگ، گل و دانه بهدليل برخوردارى از خواص بيولوزيكى متعدد

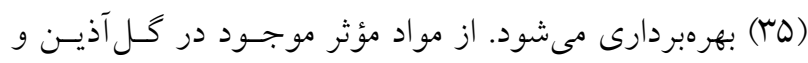

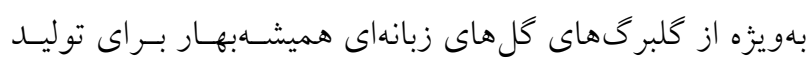

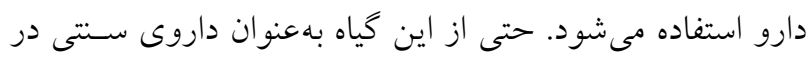

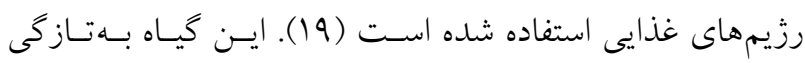

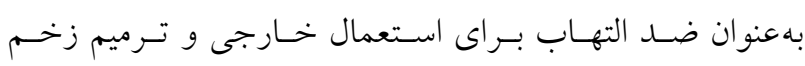

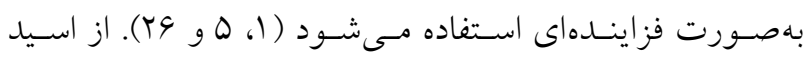

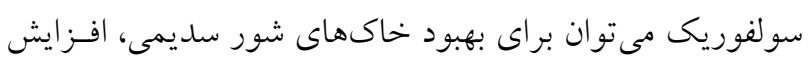

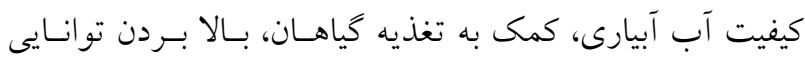

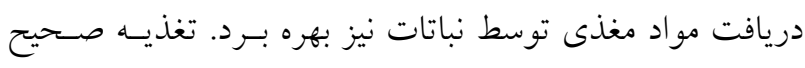

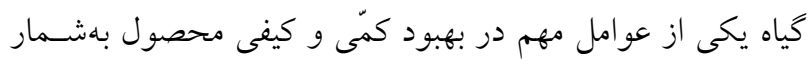

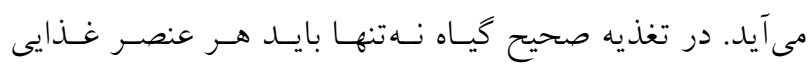

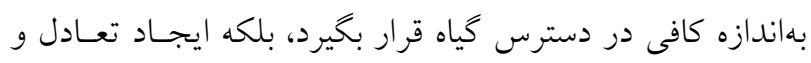

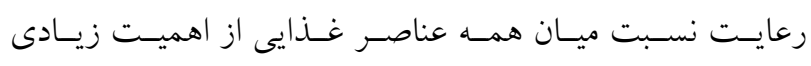

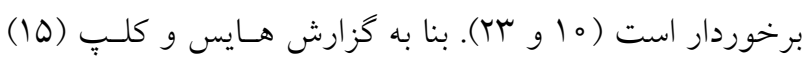

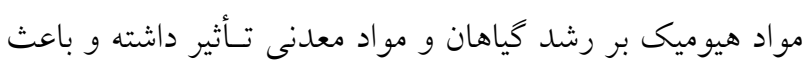

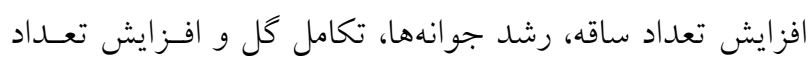

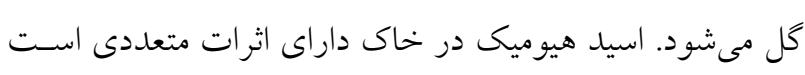

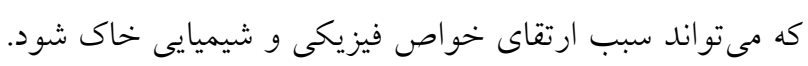

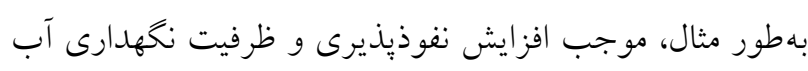

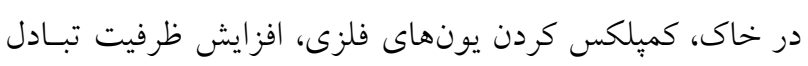

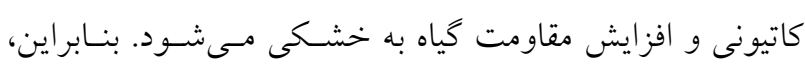

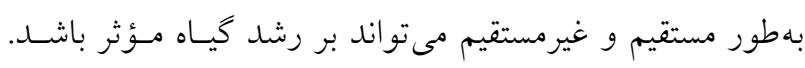

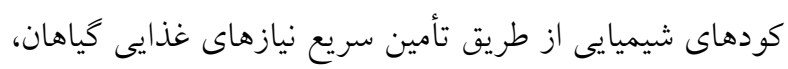

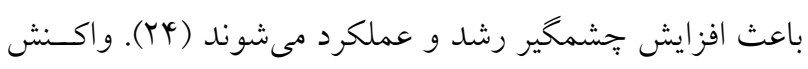

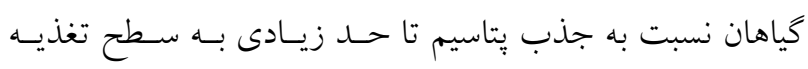

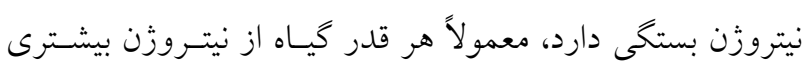

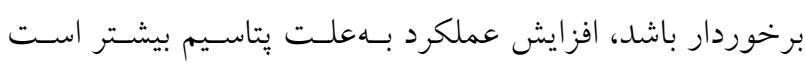

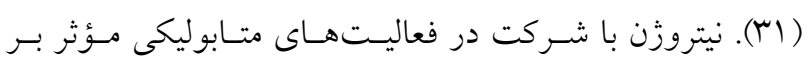

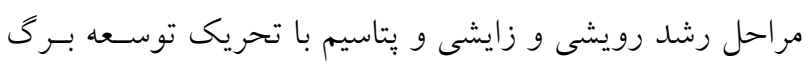


تصادفى با سه عامل و جهار تكــرار اجـرا شـــ. فـاكتور نيتـرات

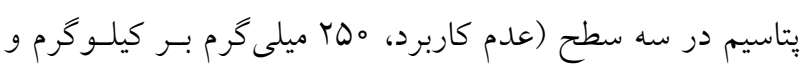

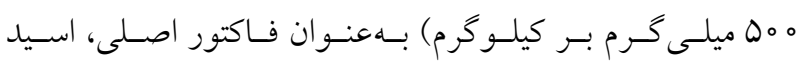

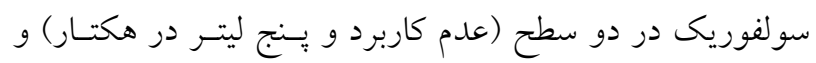

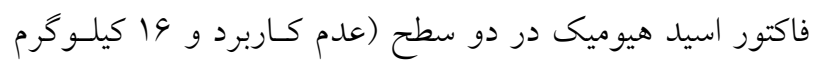

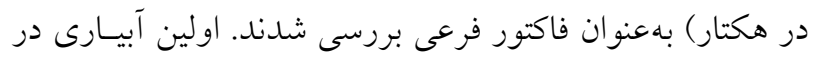

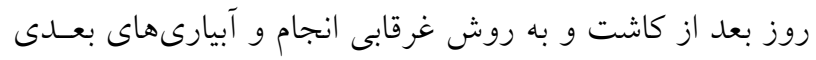

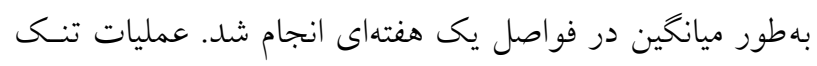

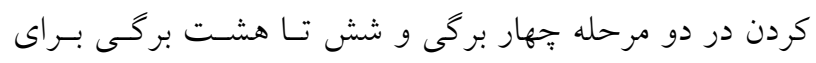

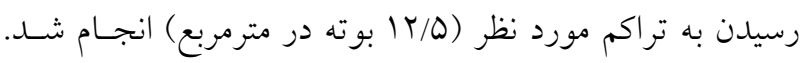

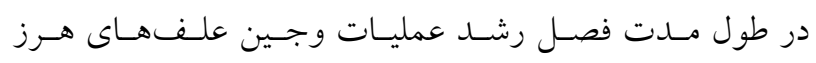
بهصورت دستى انجام گرفت. هر كـرت فرعسى داراى سـه متــر

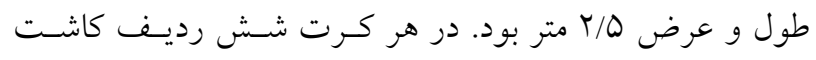
roo

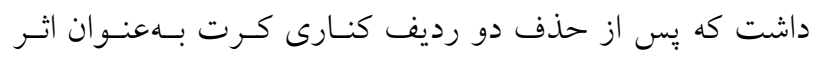

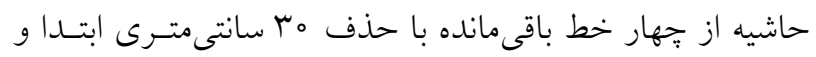

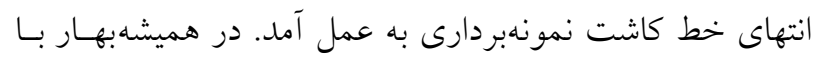

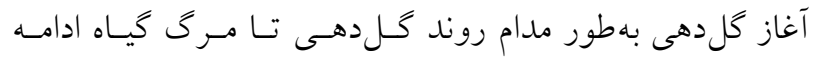

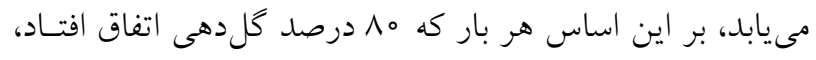

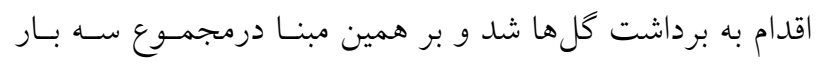

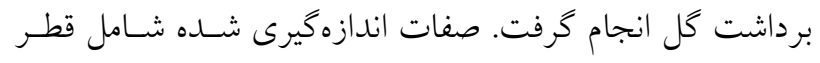

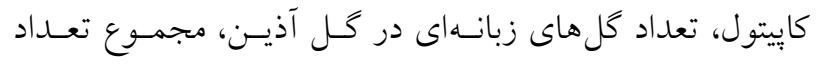

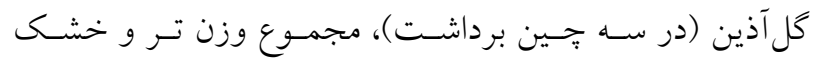

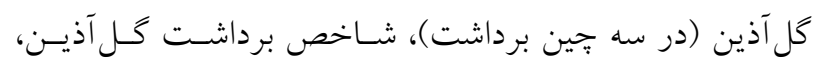

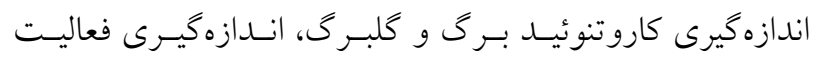

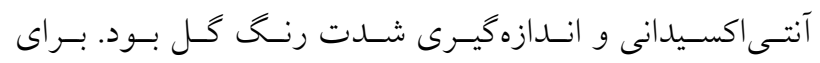

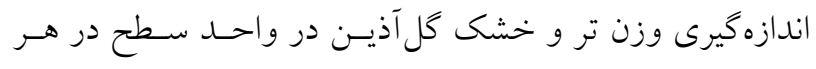

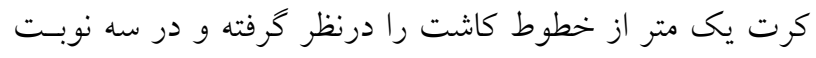

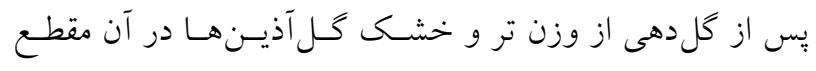

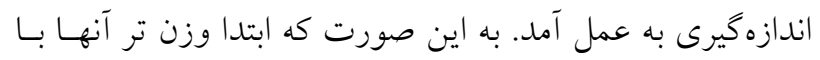

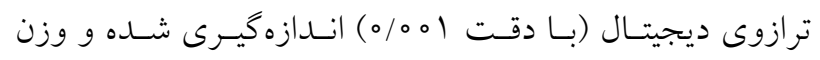

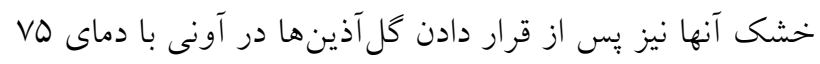
درجه سلسيوس بهمدت ^^أ ساعت يادداشت شد. به اين منظـور
بهدليل مصارف متعدد دارويى، بههاشتى، زيتتى و صـنعتى كيـاه

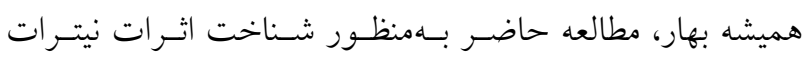

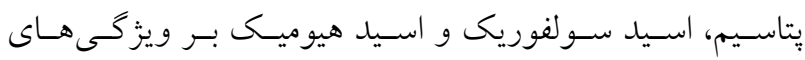

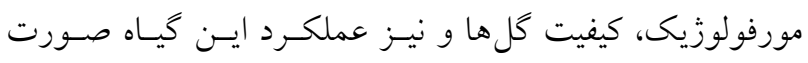
يذ بذيرفت.

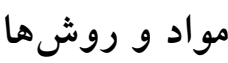

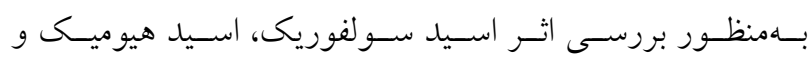

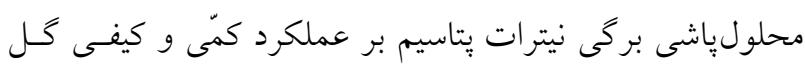

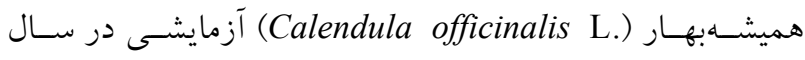

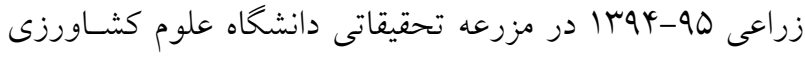
و منابع طبيعى خوزستان در مب كيلومترى شـمال شـرقى اهـواز

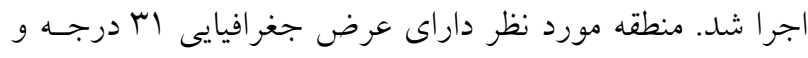

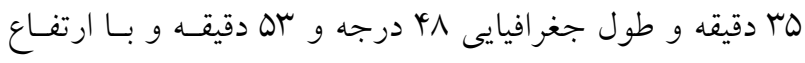

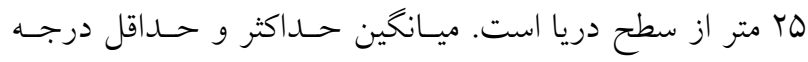

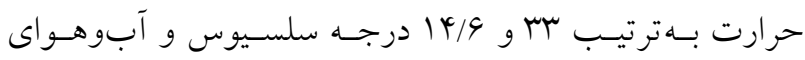

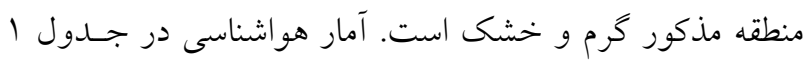
و ويزگى خاك محل آزمايش در جدول r ب درج شده است. عمليات آمادهازى زمين شامل شخم با كاو آهن بركردان ساندار

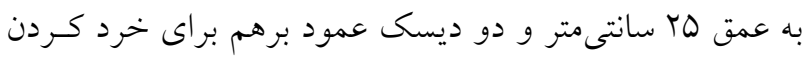

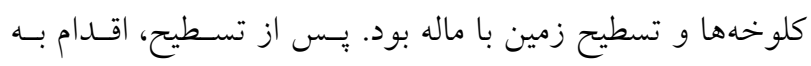

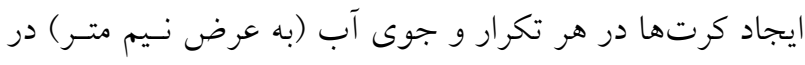

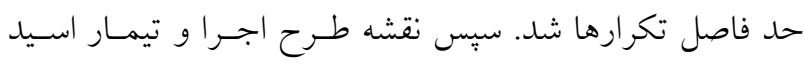

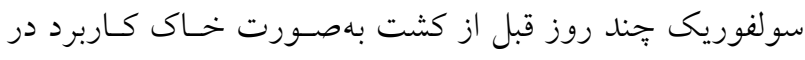

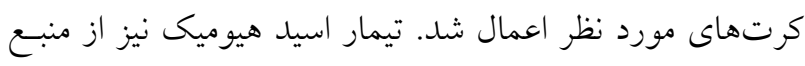

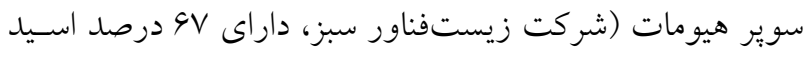

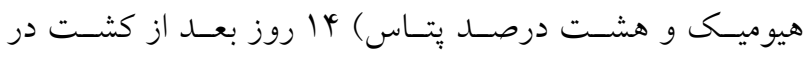

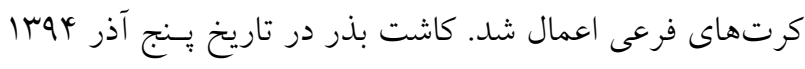

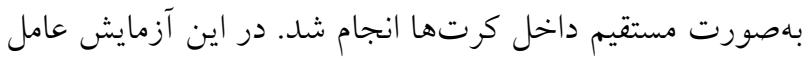

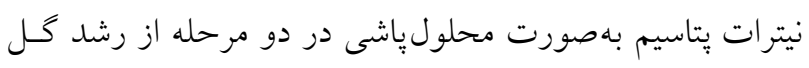

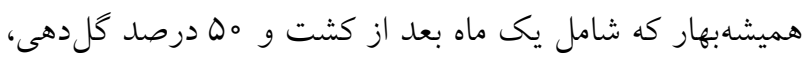

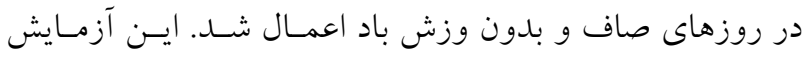

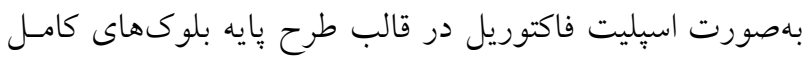


جدول ا. آمار هواشناسى ايستخاه اهواز طى دوره رويش

\begin{tabular}{|c|c|c|c|c|c|}
\hline \multirow{2}{*}{ جمع ساعت آفتابى } & \multirow{2}{*}{ تعلداد روزهاى بارانى } & جمع بارندىى & كمينه دما & بيشينه دما & \multirow[t]{2}{*}{ ماه } \\
\hline & & (ميلى متر) & \multicolumn{2}{|c|}{ (درجه سلسيوس) } & \\
\hline $199 / 4$ & 0 & $\Delta r / 4$ & $9 / 0$ & $r \circ / \Lambda$ & آذر \\
\hline $\mid \Lambda \psi / 0$ & 9 & $V 4 / 9$ & $1 / 9$ & $1 N / 9$ & دى \\
\hline$T Y \% / D$ & 0 & $\varphi / 4$ & N/9 & $r 0 / 9$ & بهمن 94 \\
\hline YOY/F & r & $r V / 4$ & $14 \pi$ & TV/G & اسفند q4 \\
\hline$r \varphi q / 4$ & 0 & $r \circ / \Lambda$ & $19 / 0$ & $r 9 / 0$ & فروردين Q9 \\
\hline$r \circ N / q$ & r & $\circ \mu$ & $r$ r/s & $r q / v$ & ارديبهشت 90 \\
\hline
\end{tabular}

جدول r. ويزگىهاى فيزيكى و شيميايى خاك مزرعه آزمايشى

\begin{tabular}{|c|c|c|}
\hline عمق نمونهبردارى ( مب-ه 9 سانتى متر) & عمق نمونهبردارى (صفر - ب سانتى متر) & ويزگى هاى خاك \\
\hline$\circ / 4 V$ & $0 / 19$ & ماده آلى (درصد) \\
\hline$r / r$ & $r / 1$ & هدايت الكتريكى (دسىزيمنس بر مول) \\
\hline$V / \Lambda$ & $V / q$ & $\mathrm{pH}$ \\
\hline $9 / \mathrm{V}$ & $9 / \pi$ & فسفر قابل جذب (ميلى گرم بر كيلوگرم) \\
\hline ITO & ler & يتاسيم قابل جذب (ميلى گرم بر گيلو گرم) \\
\hline$\circ / \wedge$ & $\circ / 0 \Delta$ & نيتروزن كل (درصد) \\
\hline 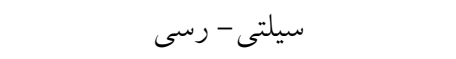 & سيلتى - رسى & بافت خاى \\
\hline
\end{tabular}

فصل رشد و يس از اتمام نمونه بردارىها شاخص برداشت كل

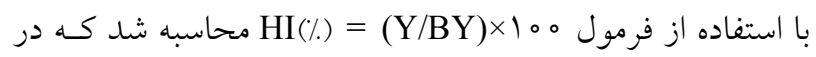

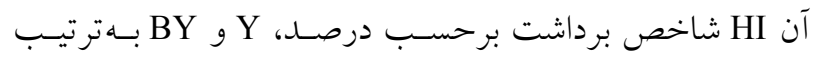

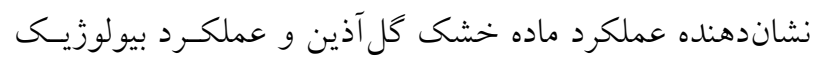

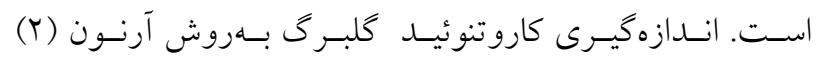

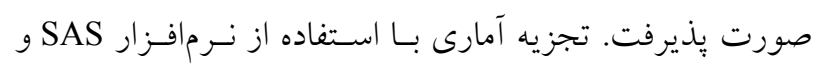

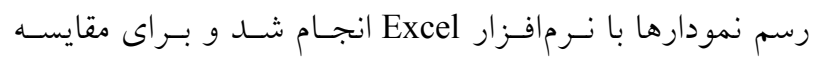

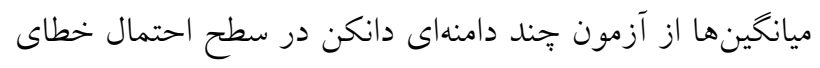
ينج درصد استفاده شد.

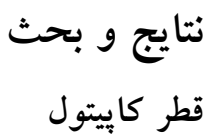
قطر كاييتول تحت تأثير تيمارهاى مـورد ارزيـابى قـرار نخرفــت
شمارش تعداد كل هاى زبانهاى در كل آذين، ه ا عدد كل در هر

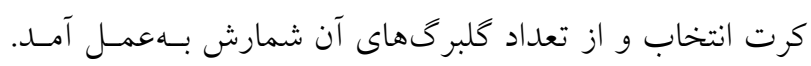

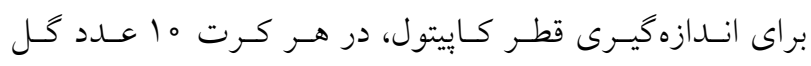

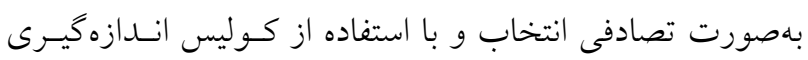

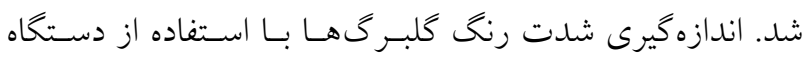

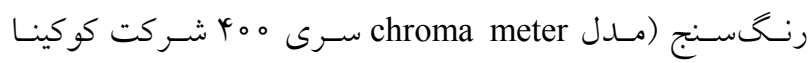

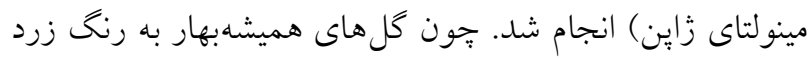

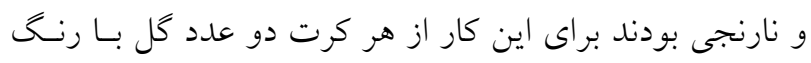
زرد و دو عدد گل با رنگ نارنجى انتخاب شد، سيس با دستخاه

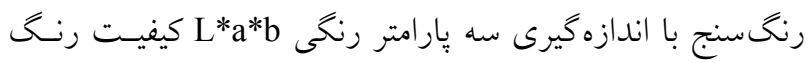

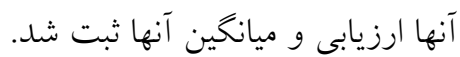

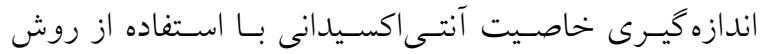

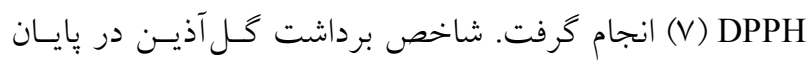


مىرسد كاربرد تـوأم نيتـرات بِتاسـيم و اسـيد سـولفوريك اثـر

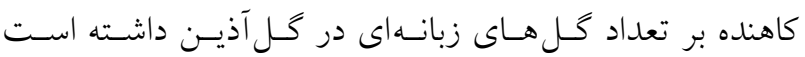

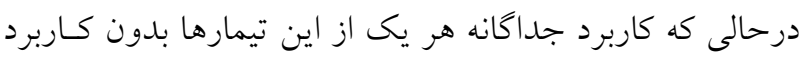

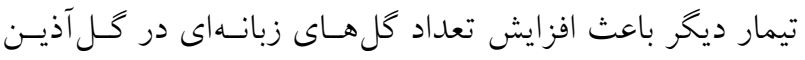

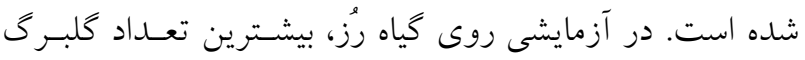
بهطور معنى دارى از كاربرد بالاترين سطح كود يتاسيم بـهدسـت

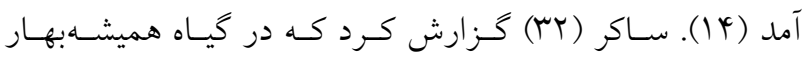

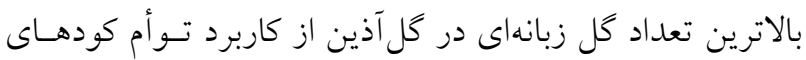

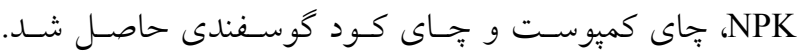

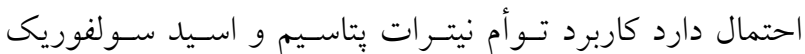
باعث افزايش و يا كاهش بيش از اندازه برخسى از عناصـر و يـا

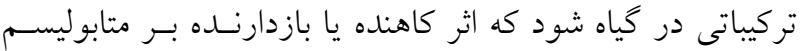

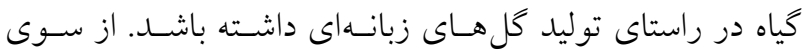
ديخر اين نتايج نشان داد كه تعداد كلهاى زبانهاى در كـل آذيـنـ مىتواند تحت تأثير عوامل تغذيهاى قرار بخيرد.

\section{مجموع تعداد كَل آذين} اثر متقابل نيترات يتاسيم × اسيد سولفوريكى بر تعداد خـل آذيـن در واحد سطح معنى دار شد (جدول r). با توجه به نتايج مقايسه

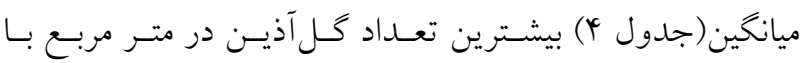

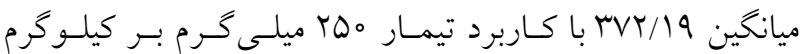
نيترات بِاسيم و كاربرد اسيد سولفوريكى بهدست آمد كه با تيمار

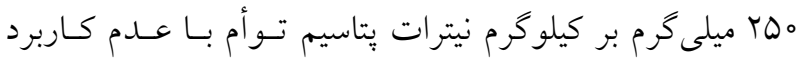

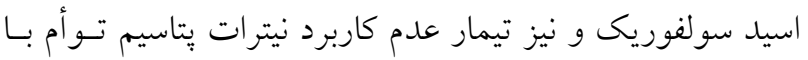

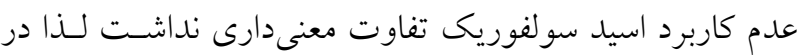

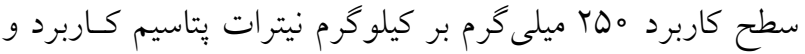

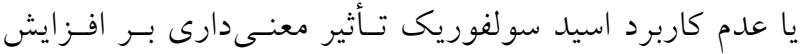
تعداد كل آذين نداشته است. در آزمايشى كلــانى اثــ كـاربرد

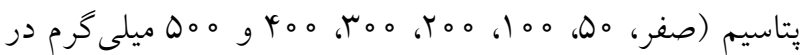

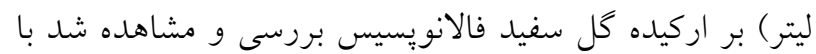
افزايش غلظت بِّاسيم تعداد و قطر كَلها افزايش يافـت (Nی).

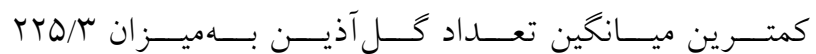

(جدول r). خسروى و همكاران (Yo) با كاربرد متانول و كلز اده

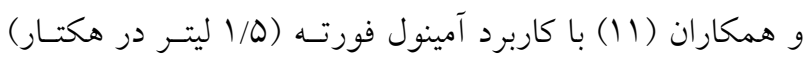
افزايش قطر كاييتول را نسـبت بـه شـاهد بـهـترتيـب در كياهـان

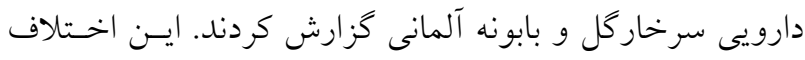
نتايج ممكن است تحت تأثير شرايط اقليمسى متفـاوت، تفـاوت كونه، تفاوت تيمارها و زمان كشت متفاوت باشد.

\section{تعداد گل هاى زبانهاى در گل آذين}

بر اساس نتايج آزمايش (جدول مَ) اثر متقابل نيتـرات يتاسـيم و

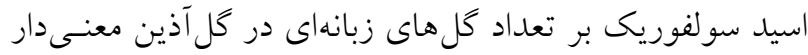
شد. مشاهدات مقايسه ميانخين (جــول \&) نشـان داد بيشـترين ميانكين تعداد كلهاى زبانهاى در كل آذيسن (هN/NT) بـا كـاربرد

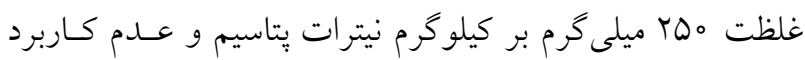
اسيد سولفوريك حاصل شد كه با تركيب تيمارى عسدم كـاربرد

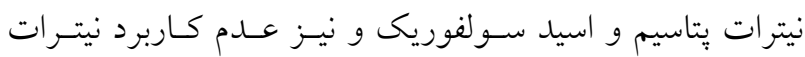
يتاسيم و كاربرد اسيد سولفوريك اختلاف معنسى دارى نداشـت. عدم وجود اختلاف معنى دار ميان تركيب تيمـارى عـدم كـاريرد

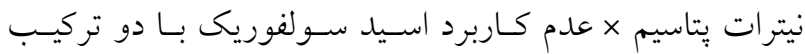

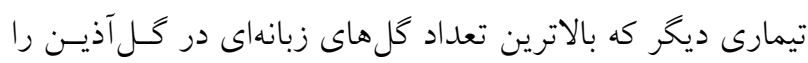

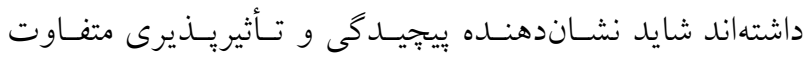
صفات زايشى در مقايسه با صفات رويشى در برابـر تيمارهـاى

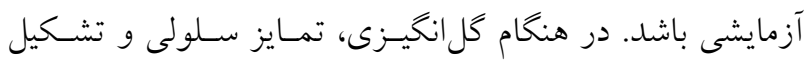

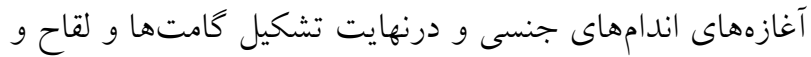
همجنين افزايش تقسيم ميوز در فاز زايشى ممكن است كلها و

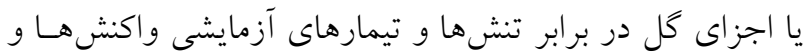
روند متفاوتى نسبت به آنجه در صفات رويشى انتظـار مسىرود

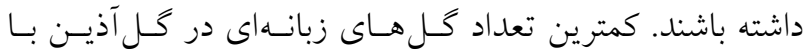

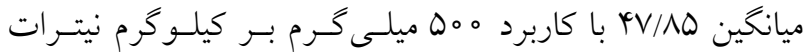

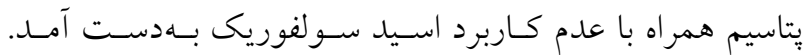

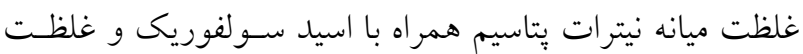

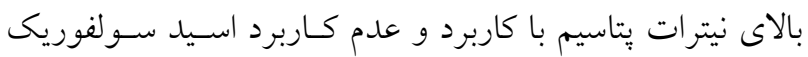

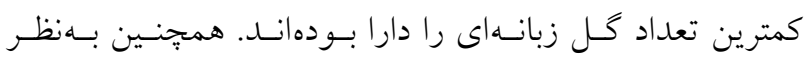




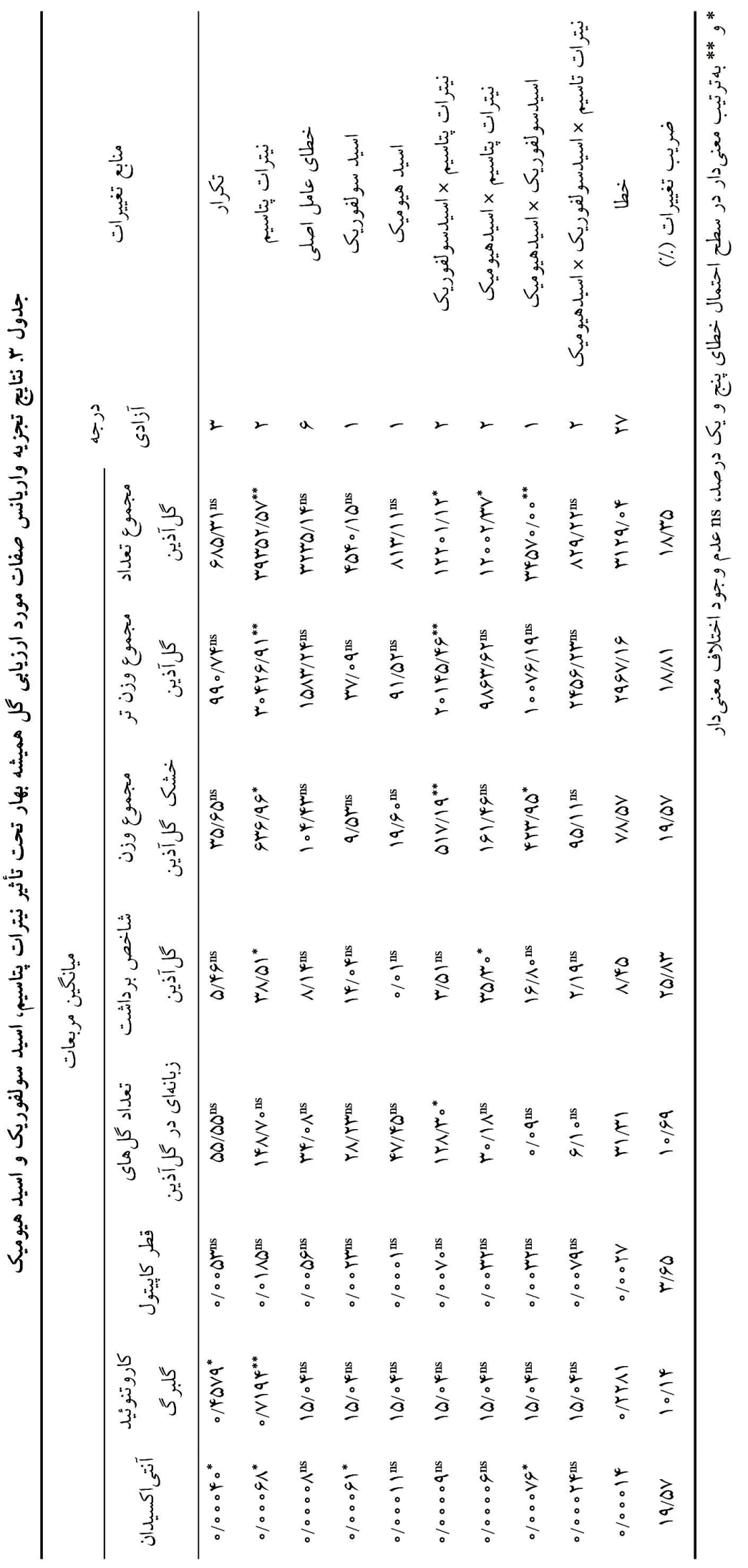


جدول \&. نتايج مقايسه ميانگين اثر متقابل نيترات بِتاسيم و اسيد سولفوريك بر صفات مورد ارزيابى گل هميشهبهار

\begin{tabular}{|c|c|c|c|c|c|}
\hline 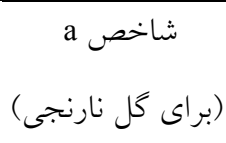 & وزن خشى گل آذين & (گرز در كل آذين & مجموع تعداد كال آذين & تعداد كل هاى زبانها & تيمار \\
\hline I س bc & $\Delta / / V \wedge^{a}$ & 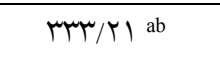 & $\mathrm{rOT} / \Lambda l^{a}$ & $\Delta Y / \Lambda Y^{a b}$ & $\mathrm{~N}_{1} \mathrm{~S}$ \\
\hline $14 / 99$ ab & $r G / Y T^{b c}$ & $r 11 / 9 \Lambda^{\circ}$ & $r \xi \circ / q r^{b}$ & $\Delta \mathscr{S} / T_{0} \mathrm{a}$ & $\mathrm{N}_{1} \mathrm{~S}_{r}$ \\
\hline IV/ara & $\Delta r / l^{a}$ & $r \Psi Q / Y T^{a b}$ & $r 99 / 01^{a}$ & $\Delta \Lambda / \Lambda \mu^{\mathrm{a}}$ & $\mathrm{N}_{r} \mathrm{~S}_{\downarrow}$ \\
\hline $1 \% / N{ }^{c}$ abc & $\Delta Y / V Y^{a}$ & $\longleftrightarrow \Lambda \circ / \uparrow \Lambda^{a}$ & $r V Y / / 9$ a & $\mathrm{kq/4G \textrm {b }}$ & $\mathrm{N}_{r} \mathrm{~S}_{r}$ \\
\hline$|N / q|^{a}$ & $\mu_{0} / \circ V^{c}$ & $199 / 0 \mathrm{~V}^{\mathrm{c}}$ & TTO/TA $\mathrm{b}$ & $\left\lceil V / \Lambda D^{b}\right.$ & $\mathrm{N}_{r} \mathrm{~S}_{1}$ \\
\hline$q / V V^{c}$ & $Y T / 9 D$ ab & $T V Q / \circ V b c$ & $r \Delta Q / \circ q^{b}$ & $|\wedge \wedge / \mu| b$ & $\mathrm{~N}_{r} \mathrm{~S}_{r}$ \\
\hline
\end{tabular}

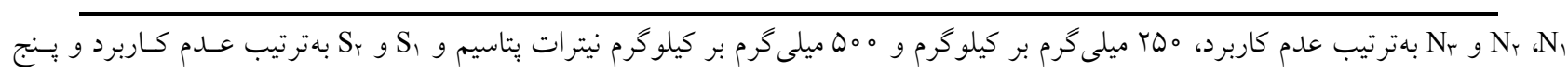

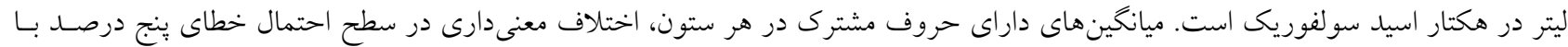
يكديخر ندارند.

ميلى گرم بـر كيلـوخرم نيتـرات بِّاسـيم و عسدم كـاربرد اسـيد هيوميك (19V/90) مشاهده شد كه نشاندهنده از فراتر از نياز

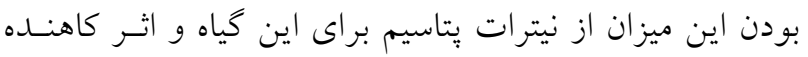

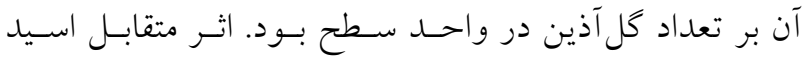

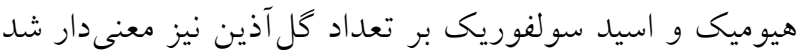
(جدول ץ). وقتى هيوميك اسيد مصرف نشــ، مصـرف اسـيد

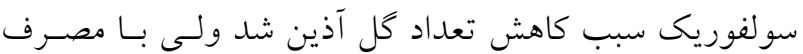
هيوميك اسيد بين مصرف و عــدم مصـرف سـولفوريك اسـيد

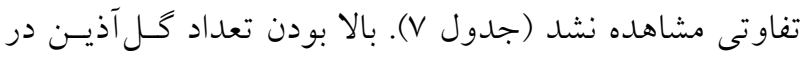
تركيب تيمارى عدم كاربرد اسيد سولفوريك و اسيد هيوميكى

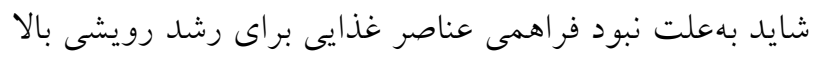

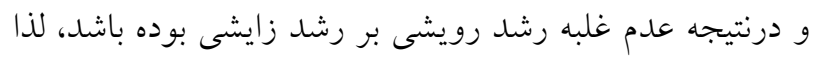

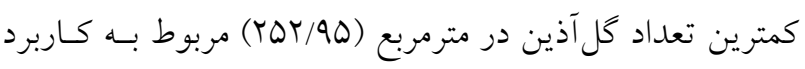

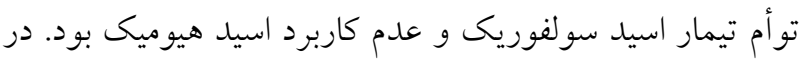

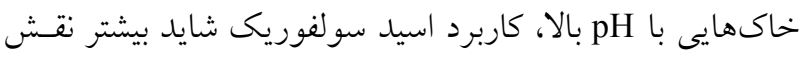

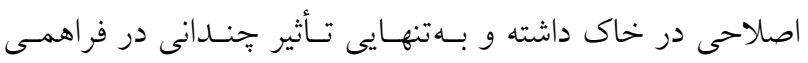

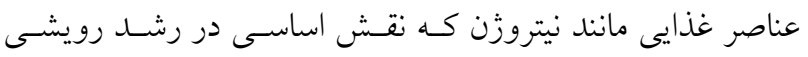

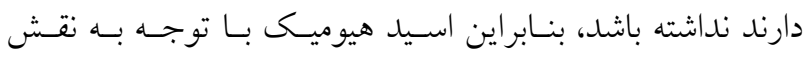
تغذيهاى كه دارد مىتواند تا حدودى جبران اين كاستى را كند.
كل در متر مربع مربوط بـهـ تيمـار غلظـت مله ميلسى كـرم بـر كيلو گرم نيترات يتاسيم و عدم كاربرد اسـيد سـولفوريك بــود.

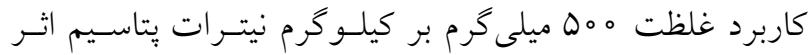
منفى بر تعداد گل آذين داشت و اين دليلى بر بازدارندگى ايسن

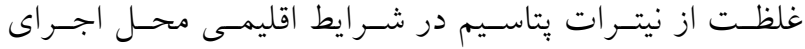
آزمايش بود. اثر متقابل نيترات يتاسيم و اسـيد هيوميـك بـراى

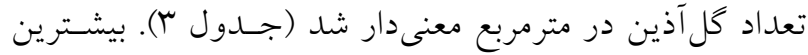

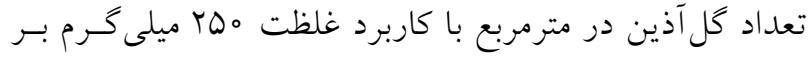
كيلو گرم نيترات پِاسيم توأم با كاربرد اسيد هيوميك (YVI/TO)

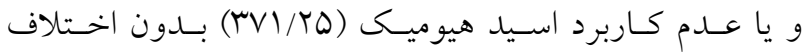
معنى دار بهدست آمد. اين دو تركيب تيمارى با تركيب تيمارى

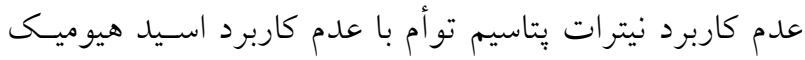
اختلاف معنىدارى نداشت (جــدول 9). در آزمايشى كـاربرد

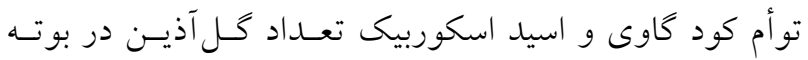
هميشهبهار را نسبت به شاهد نزديك به دو برابـر افزايش داد

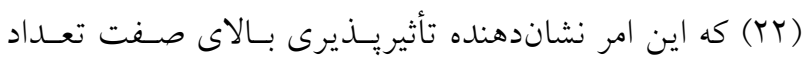

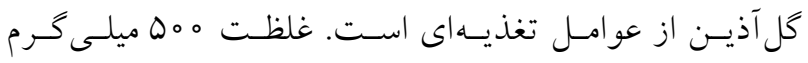

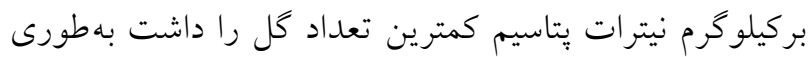

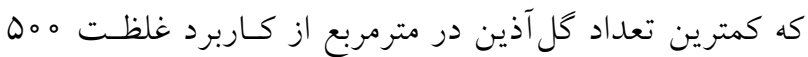




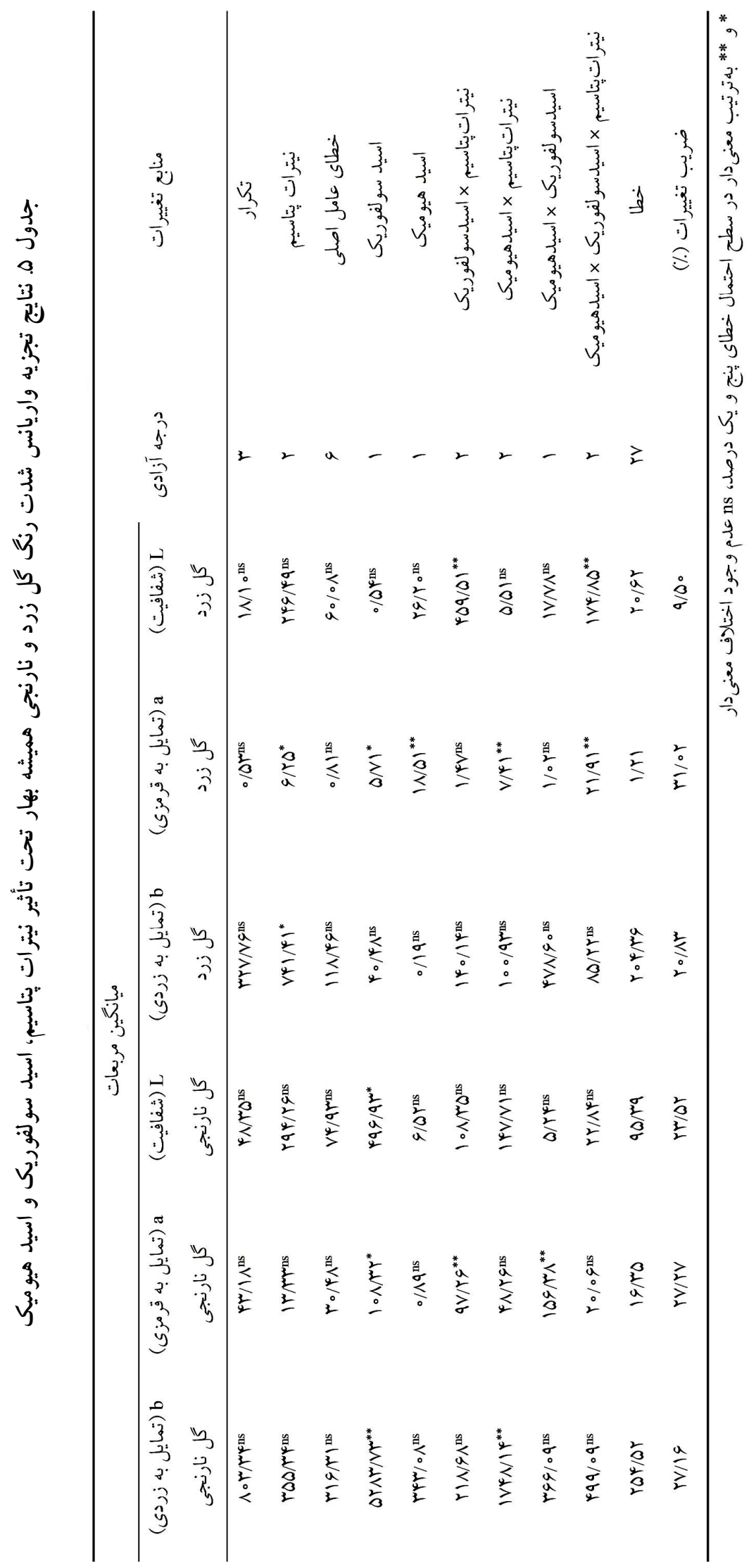


جدول و. نتايج مقايسه ميانخين اثر متقابل نيترات يتاسيم و اسيد هيوميك بر صفات مورد ارزيابى گل هميشهبهار

\begin{tabular}{|c|c|c|c|}
\hline (كاخص نارنجى) & شاخص برداشت گل آذين & مجموع تعداد گل آذين & تيمار \\
\hline$\Delta F / 19^{b}$ & $11 / 99^{a b c}$ & $T Y Q / 10^{a b}$ & $\mathrm{~N}_{1} \mathrm{H}_{2}$ \\
\hline$\Delta V / V c^{b}$ & $1 Y / \Delta Y^{a}$ & $r G \wedge / \Psi \subset \Delta^{b c}$ & $\mathrm{~N}, \mathrm{H}_{r}$ \\
\hline $01 / 10^{b}$ & $N / 9 \mu^{c}$ & $r V \backslash / r \Delta^{a}$ & $\mathrm{~N}_{\uparrow} \mathrm{H}_{\uparrow}$ \\
\hline$\Delta \psi / \mu r a$ & $10 / 0 \mathrm{cbc}$ & $r V \backslash / T \Delta^{a}$ & $\mathrm{~N}_{\curlyvee} \mathrm{H}_{\curlyvee}$ \\
\hline $99 / \mathrm{V}^{\mathrm{ab}}$ & $\mid \mu / \circ \wedge^{a b}$ & $19 V / 90^{\mathrm{c}}$ & $\mathrm{N}_{r} \mathrm{H}_{\curlywedge}$ \\
\hline$Y q / Y Y^{b}$ & $\Lambda / 9 V^{c}$ & $r \wedge \& /\left.D\right|^{b}$ & $\mathrm{~N}_{r} \mathrm{H}_{r}$ \\
\hline
\end{tabular}

N N $N_{1}$

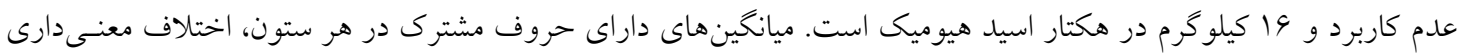
در سطح احتمال خطاى ينج درصد با يكديخر ندارند.

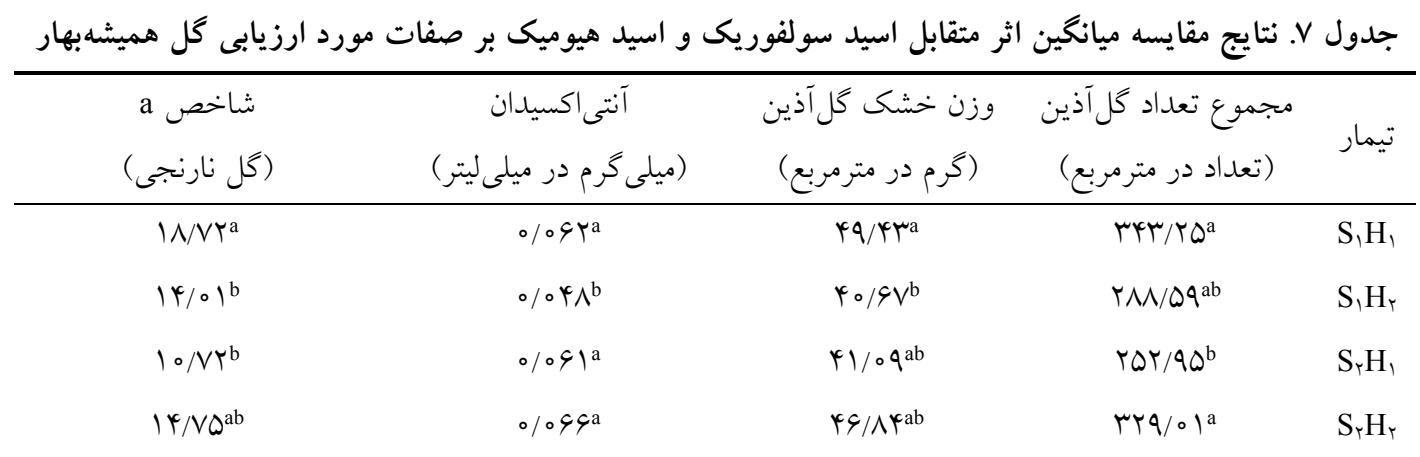

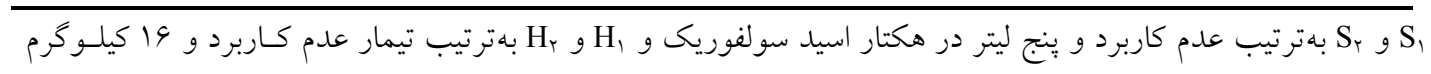
در هكتار اسيد هيوميك است و ميانكين هاى داراى حروف مشترى در هر سـتون، اخـتلاف معنسىدارى در سـطح احتمـال خطاى ينج درصد با يكديخر ندارند.

از سوى ديخر دى آنجلو و همكاران (N) معتقدند مواد سنتز شده در مرحله كلدهيى بهطور عمله به سمت اندامهاى زايشى منتقل مىشود. البته صفت وزن تر اندامهاى گيـاهى از نظـر برخسى از

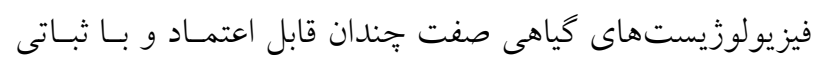
نيست زيرا اين صفت در مقاطع زمانى كوتاه بهشدت تحت تأثير عوامل زيستى و غير زيستى قرار داشته و تغيير مىكند و همسين امر تفسير نتايج بهدست آمله را مشكل مىسازد. در شرايطى كـه نيترات يتاسيم اعمال نشــ نقـش كـاربرد اسـيد سـولفوريك در افـزايش وزن تـر كـلـ آذيسن كـاهش يافـت و كمتـرين وزن تـر كل آذين نيز با ميانخين 199/0V كرم در مترمربع مربوط به تيمار
مجموع وزن تر گَل آذين

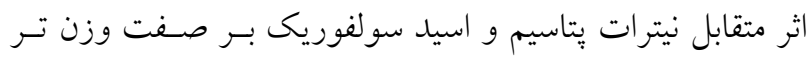

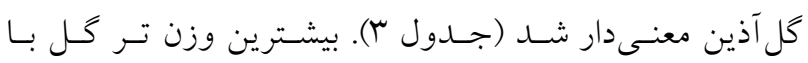
ميانخين ميلى گرم بر كيلوگرم نيترات يتاسيم و كاربرد اسـيد سـولفوريك

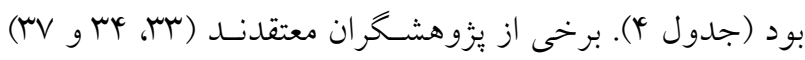

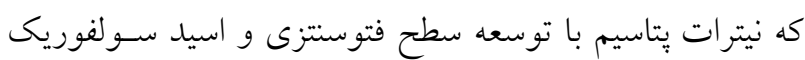
با افزايش انتقال عناصر از ريسشه به اندام هوايى و تجمـع مـواد

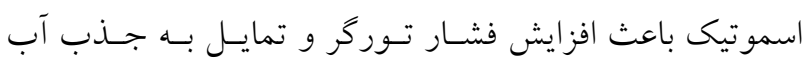
بيشتر شده و به اين صورت بر وزن تر گل مؤثر واقع مىشـوند. 
افزايش وزن خشك كـل آذيسن كـه جـزء بخــش زايشـى اسـت

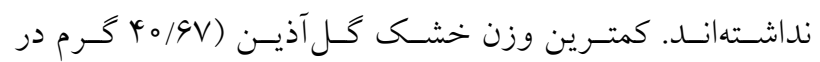
مترمربع) مربوط به عدم كاربرد اسيد سولفوريك و كاربرد اسـيد

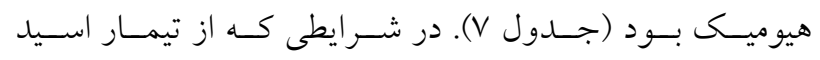

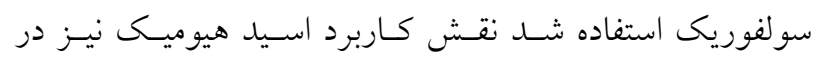

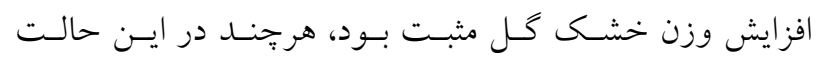

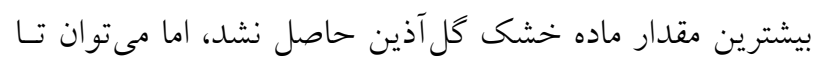
حدودى به نقش مثبت استفاده همزمان اسيد سولفوريك و اسيد

$$
\text { هيو ميك يى برد. }
$$

شاخص برداشت گل آذين

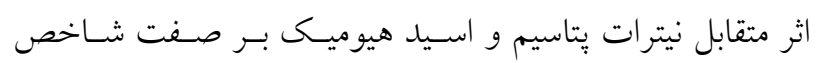

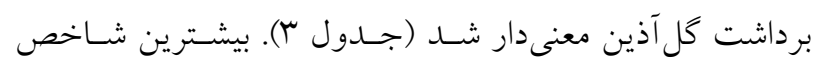
برداشت مربوط به تيمار عدم كـاربرد نيتـرات يتاسسيم و كـاربيرد

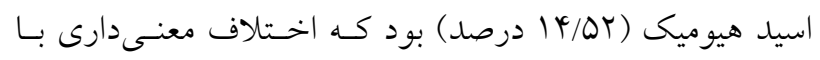

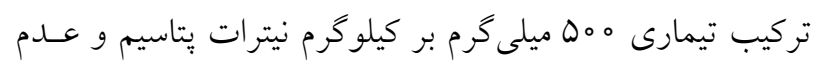

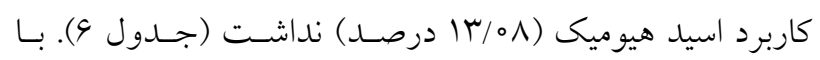

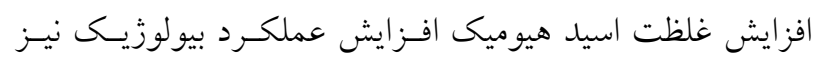
بهوقوع بيوست كه اين شايد بهدليل وجود عناصر ضرورى رشد ميد

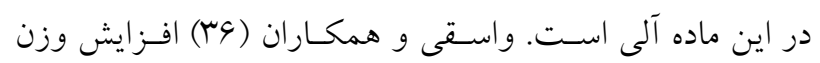

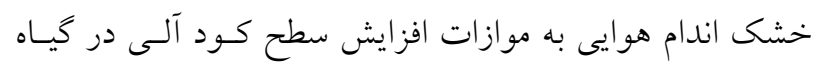
اسفناج را گزارش كردند. با افزايش سطوح نيتـرات يتاسـيم اثـر

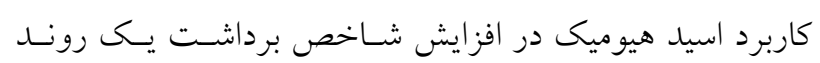

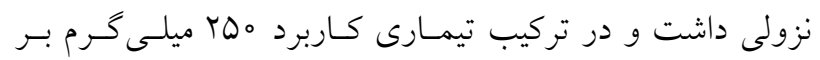

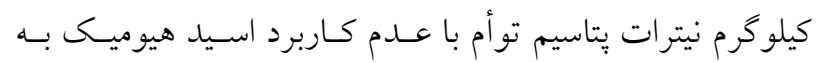

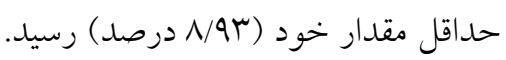

\section{كاروتنوئيد گلبرى}

كل هاى هميشهبهار طيف متنوعى از تركيـبـهـاى كاروتنوئيسدى

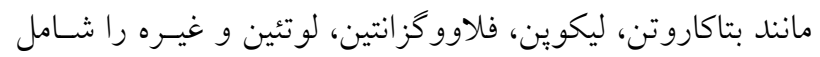

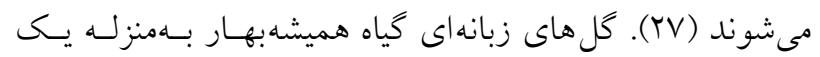

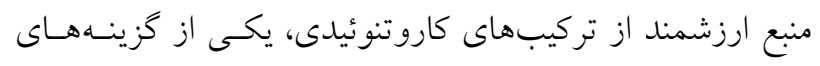

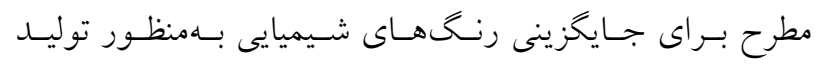

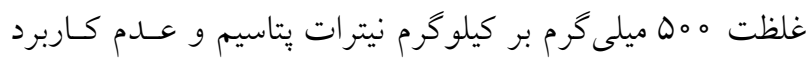

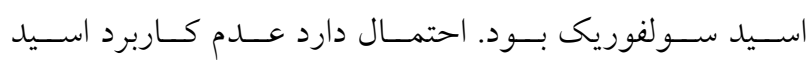

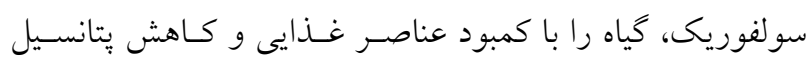

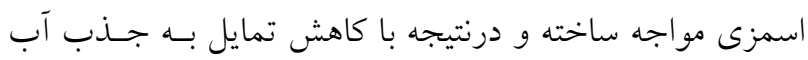
باعث كاهش وزن تر كل شده است.

\section{مجموع وزن خشك گل آذين}

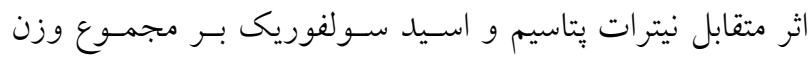

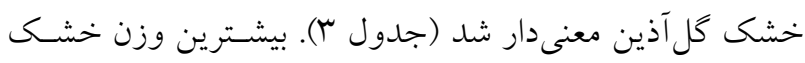

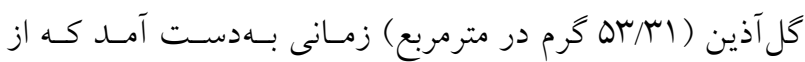

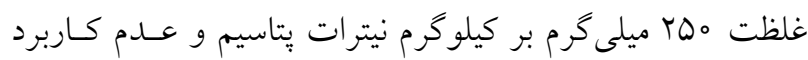

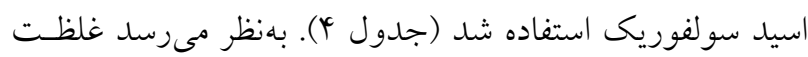

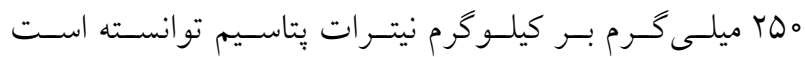

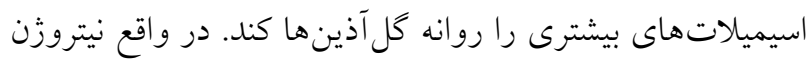
با شركت در فعاليتهاى متابوليك مؤثر بر مراحل رشد رويشى رلي و زايشى و يتاسيم با تحريك توسعه برى و ظرفيـت فتوسـتنزى

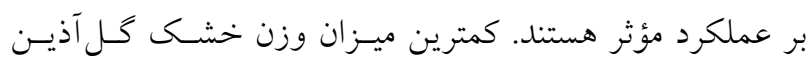

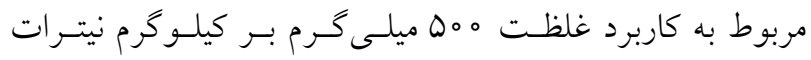

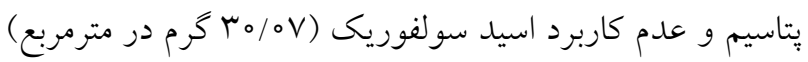
بود كه با تركيب تيمارى عدم كاربرد نيتـرات يتاسـيم و كـاربرد

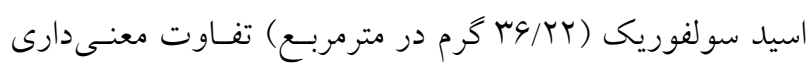

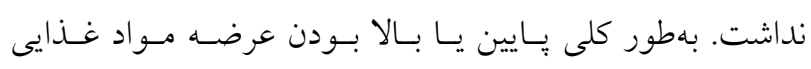
مىتواند در تعادل و نسبت رشد رويشى و زايشى كيـاه تـأثير بحذارد. اثر متقابل اسيد سولفوريك و اسيد هيوميك نيز معنى دار شد (جدول ץ). بيشترين وزن خشك كل آذين از تركيب تيمارى

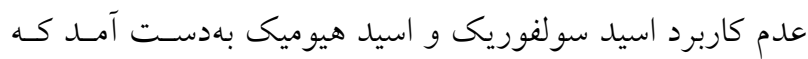
بهجز با تركيب تيمارى عدم كاربرد اسيد سـولفوريكى و كـاربرد

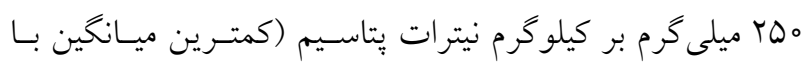

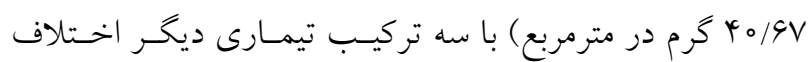
معنى

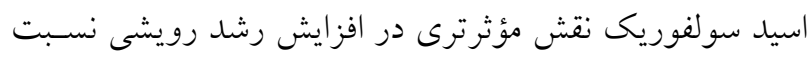

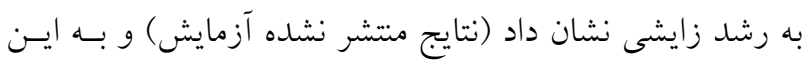
ترتيب اين دو عامـل بـهــور مستقيم نقـش قابـل تـوجهى در 
متقابل اسـيد هيوميـى و اسـيد سـولفوريك بـر ميـزان فعاليـت

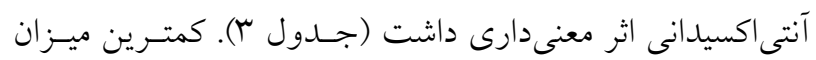

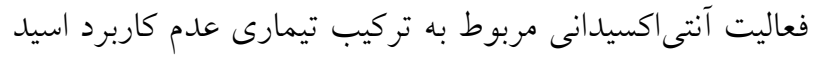

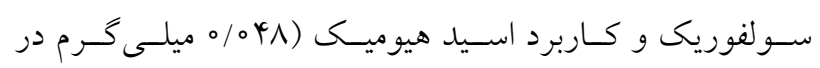

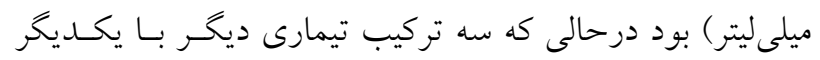

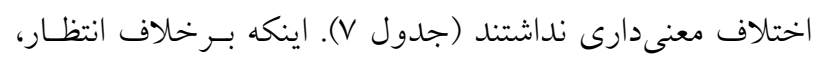
تركيب تيمارى عدم كاربرد اسيد سولفوريك و عدم كاربرد اسيد

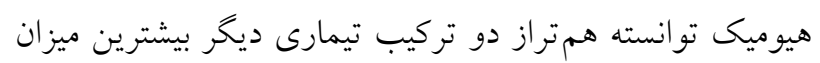

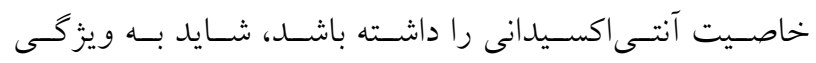

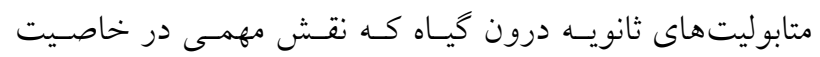

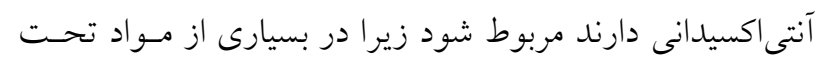

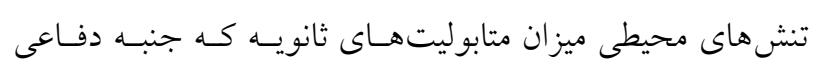

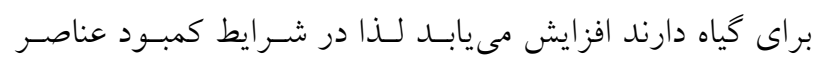

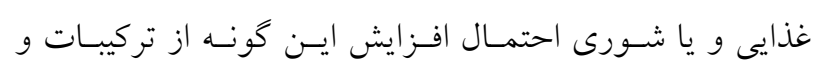

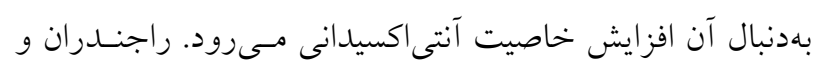

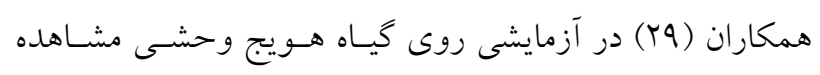

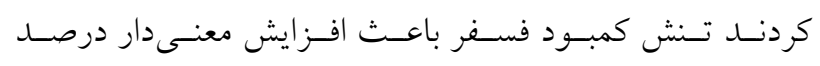
آنتوسيانين ها كه خاصيت آنتى اكسيدانى دارند در مقايسه با تيمار

شاهد شد.

\section{شدت رنگ گل}

\section{درجه شفافيت (L) براى كل هاى زرد رنح}

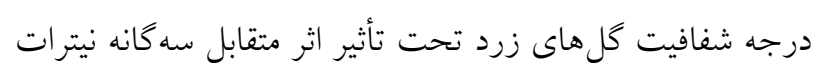

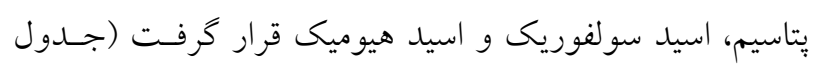

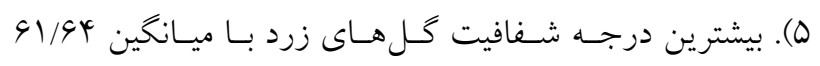

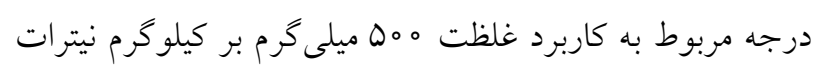

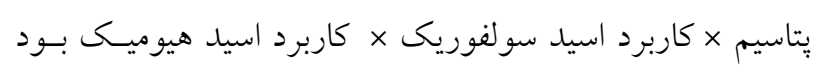

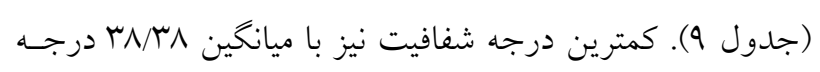

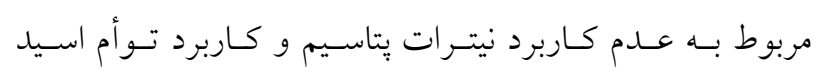

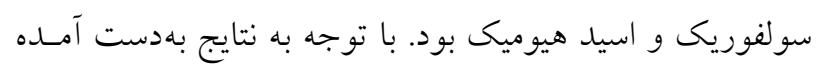

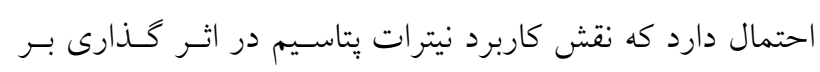

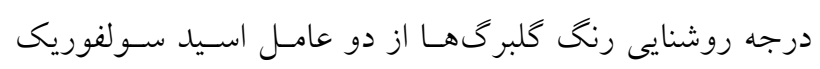

رنخهاى طبيعى و دوستدار محيط زيست است (Y) (I). به نظـر

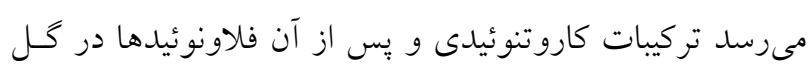

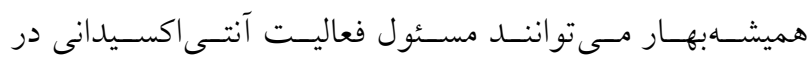

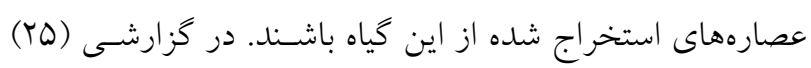

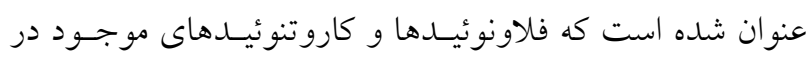

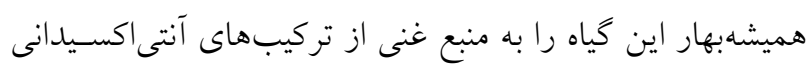

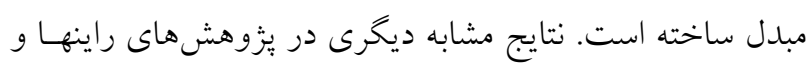

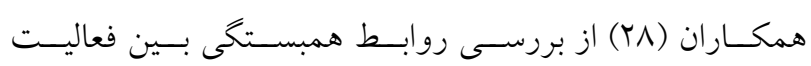

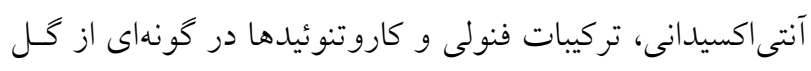

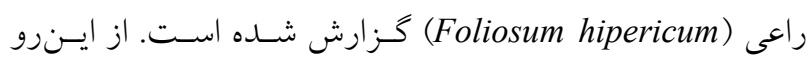

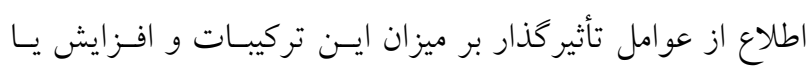

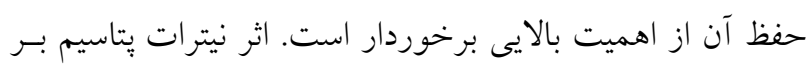

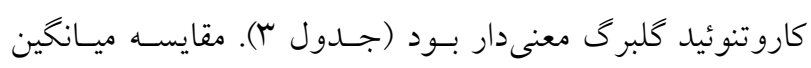

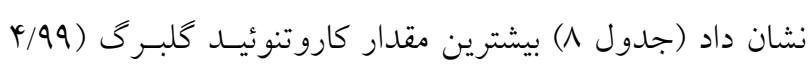

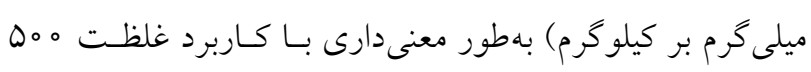

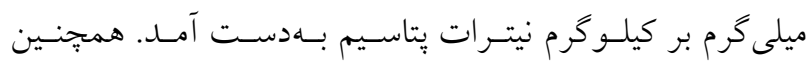

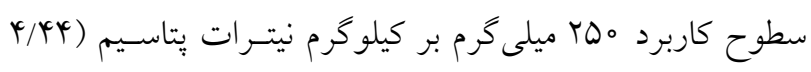

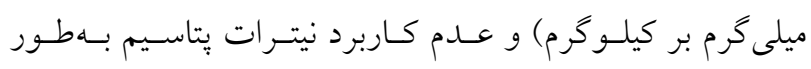

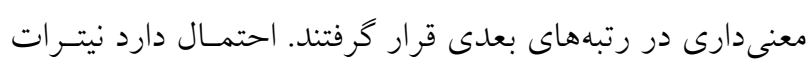

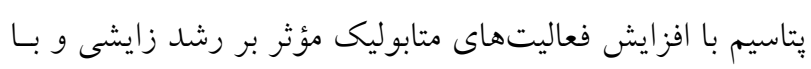

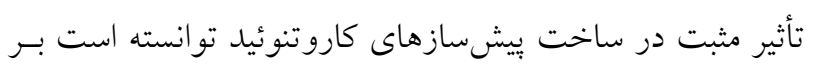

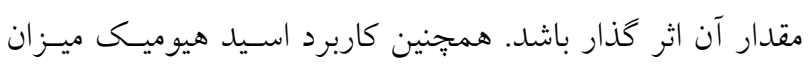

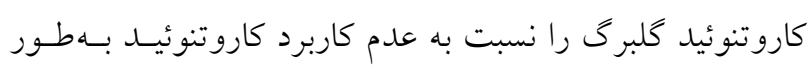
معنى دارى افزايش داد (جدول ^).

\section{آنتى اكسيدان}

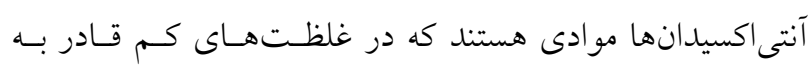

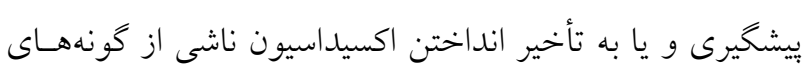

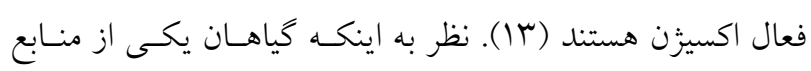

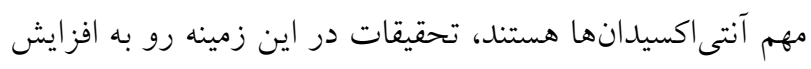

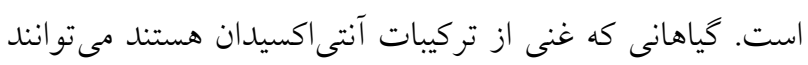
باعث حفاظت سلولها از آسيبهاى اكسيداتيو شوند (T) (Y). اثـر 
جدول ^ـ نتايج مقايسه ميانخين صفات مورد ارزيابى گل هميشهبهار تحت تأثير نيترات بتاسيم، اسيد سولفوريك و اسيد هيوميك

\begin{tabular}{|c|c|c|c|c|c|}
\hline 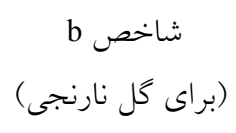 & $\begin{array}{c}\text { L شاخ كل نارنجى) } \\
\text { (براى }\end{array}$ & (براى كل زرد) & (ميلى گرم در ميلى ليتر) & (ماروتنوئيد كلبرى كرم كيلو كرم) & 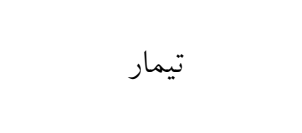 \\
\hline & & & & & نيترات يتاسيم \\
\hline$\Delta \& / 9 / 1^{a}$ & $\mu Y_{/} / 9 \Lambda^{b}$ & $91 / 01^{b}$ & $\circ / 09 \wedge^{\mathrm{a}}$ & $Y / N I^{b}$ & شاهد \\
\hline $9 r / 90^{\mathrm{a}}$ & $x y / 4 q^{a}$ & $q \mathrm{~V} / \mathrm{V} \varphi^{\mathrm{ab}}$ & $\% 990 a b$ & $r / 4 k c$ & •هT ميلى گرم بر كيلو گرم \\
\hline \multirow[t]{2}{*}{ ( ) } & $\varphi \Delta / \wedge^{\mathrm{a}}$ & $V \varphi / r q^{a}$ & $\circ / \circ \Delta r^{b}$ & $r / 99^{a}$ & ه مه ميلى گرم بر كيلو گرم \\
\hline & & & & & اسيدسولفوريك \\
\hline $\mathrm{V} / 9 \mathrm{Va}$ & $\varphi \Delta / 1 Q^{a}$ & $99 / M^{a}$ & $\circ / \circ \Delta V^{a}$ & $r / 99^{a}$ & شاهد \\
\hline \multirow[t]{2}{*}{$Y Q / V q^{b}$} & $r V / M^{b}$ & $9 V / M^{\prime a}$ & $\circ / 09 \mu^{\mu}$ & $r / 90^{\mathrm{a}}$ & ينج ليتر در هكتار \\
\hline & & & & & اسيدهيوميك \\
\hline$\Delta \& / \Delta^{a}$ & $\varphi \circ / 9 \Delta^{a}$ & $9 N / 0 \Lambda^{a}$ & $\circ / \circ r^{a}$ & $r / \wedge q^{a}$ & 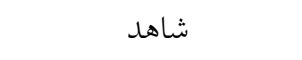 \\
\hline $91 / 11^{\mathrm{a}}$ & $\Psi T / \Lambda^{\mathrm{a}}$ & GN/GHa & $\circ / \circ \Delta q^{a}$ & $r / Q f b$ & 19 كيلو كرم در هكتار \\
\hline
\end{tabular}

حروف مشابه در هر ستون و در هر عامل آزمايشى، نشانگر عدم وجود تفاوت معنىدار در سطح احتمال خطاى ينج درصد است.

جدول 9. كل هميشه بهار

\begin{tabular}{|c|c|c|}
\hline شاخص a (براى كل زرد) & شاخص L (براى گل زرد) & 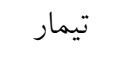 \\
\hline$Q / T r^{a}$ & KYMTdef & $\mathrm{N}_{1} \mathrm{~S}_{1} \mathrm{H}_{1}$ \\
\hline$\Delta / \circ r^{\mathrm{ab}}$ & $\varphi \Delta / 1 \varphi^{\text {def }}$ & $\mathrm{N}_{1} \mathrm{~S}_{\curlyvee} \mathrm{H}_{\uparrow}$ \\
\hline$r / 1 q^{\mathrm{bc}}$ & $Y \mu / 4 V^{d e f}$ & $\mathrm{~N}_{1} \mathrm{~S}_{1} \mathrm{H}_{r}$ \\
\hline$\circ / N q^{d}$ & $\mu \wedge / \Lambda^{f}$ & $\mathrm{~N}_{\uparrow} \mathrm{S}_{r} \mathrm{H}_{r}$ \\
\hline$r / 9 q^{a b}$ & $\varphi q / \gamma^{\mathrm{cd}}$ & $\mathrm{N}_{r} \mathrm{~S}_{1} \mathrm{H}_{l}$ \\
\hline$\Delta / 1^{\mathrm{ab}}$ & $\kappa V / N r^{c d e}$ & $\mathrm{~N}_{r} \mathrm{~S}_{r} \mathrm{H}_{\uparrow}$ \\
\hline$\varphi / N^{a b}$ & $\Delta N / Y \Delta^{\mathrm{ab}}$ & $\mathrm{N}_{r} \mathrm{~S}_{1} \mathrm{H}_{r}$ \\
\hline$r / 1 \varphi^{\mathrm{cd}}$ & rN/V $r^{f}$ & $\mathrm{~N}_{r} \mathrm{~S}_{r} \mathrm{H}_{r}$ \\
\hline$\varphi / \varphi l^{a b}$ & $0 . / 9 /$ bcd & $\mathrm{N}_{r} \mathrm{~S}_{1} \mathrm{H}_{l}$ \\
\hline$\circ / N r^{d}$ & $\Delta \Delta / 9 q \mathrm{abc}$ & $\mathrm{N}_{r} \mathrm{~S}_{r} \mathrm{H}_{4}$ \\
\hline$\circ / 9 \gamma^{d}$ & $\mathrm{r} Q / \wedge \omega^{\mathrm{ef}}$ & $\mathrm{N}_{r} \mathrm{~S}, \mathrm{H}_{r}$ \\
\hline$\varphi / \uparrow^{4 a b}$ & $91 / 94 a$ & $\mathrm{~N}_{r} \mathrm{~S}_{r} \mathrm{H}_{r}$ \\
\hline
\end{tabular}

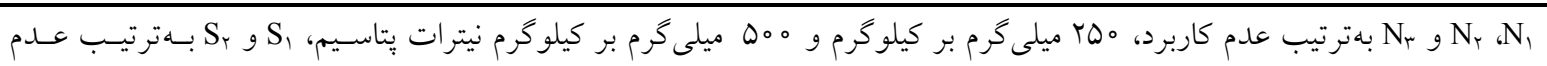

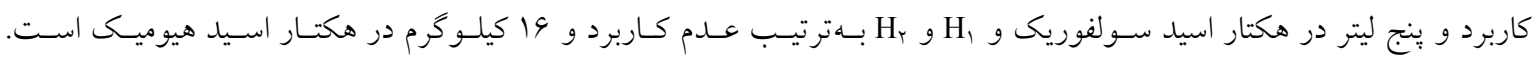

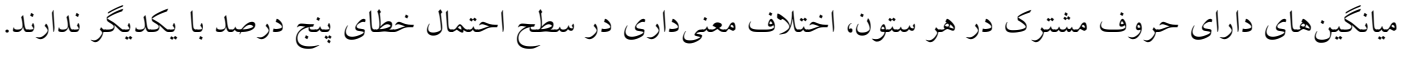


كاربرد اسيد سولفوريك بر متابوليتهاى مربوط بـهـ مؤلفـهـــاى

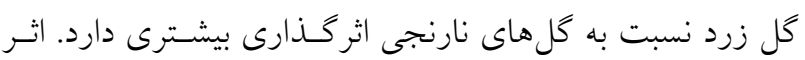

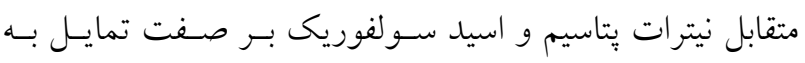

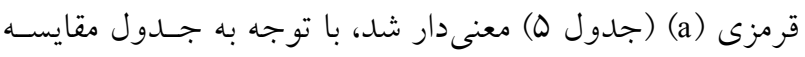

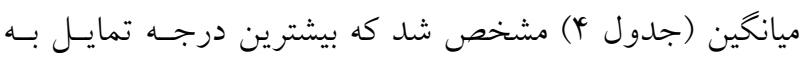

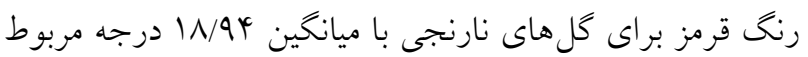

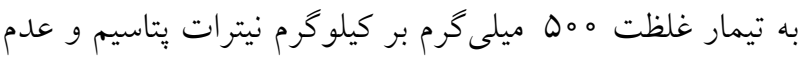
كاربرد اسيد سولفوريك است و از اين نظر اختلاف معنسدارى

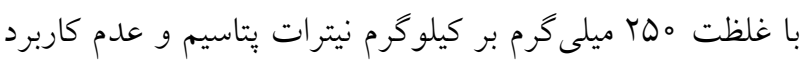

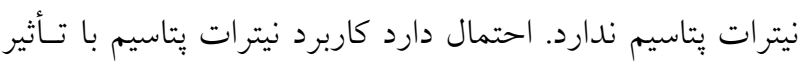

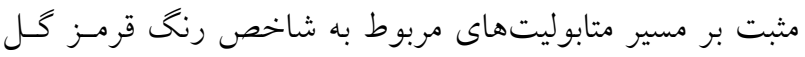

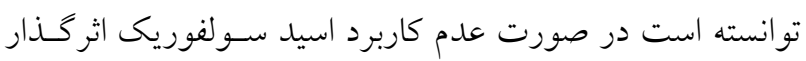

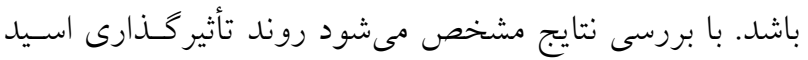

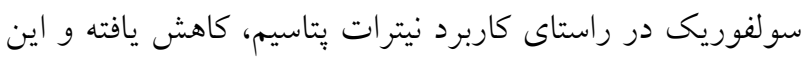

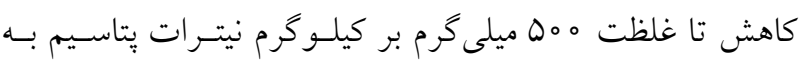

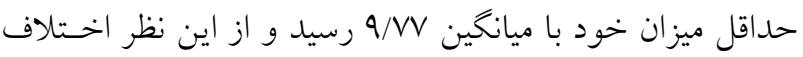

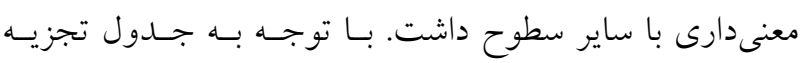

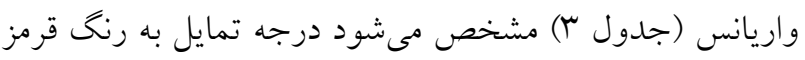

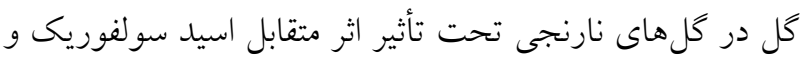

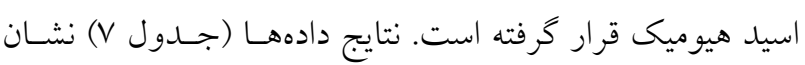

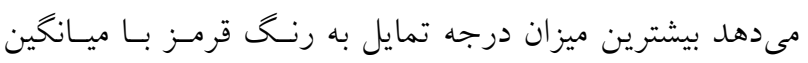
I M/VT

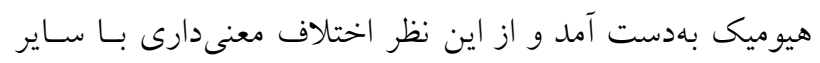

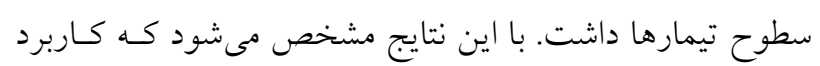

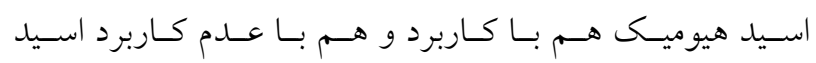

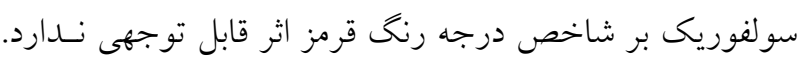

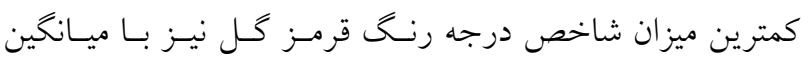
ا ا درجه مربوط به تيمـار شـاهد اسـيد هيوميكى و كـاربرد

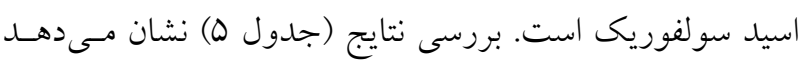

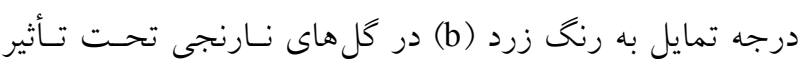
اسيد سولفوريك قرار كرفته است. نتـايج مقايسـهــاى ميـانخين

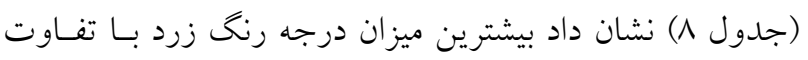

و اسيد هيوميك بيشتر باشد. نتايج اتـر متقابـل نيتـرات بِتاسـيم،

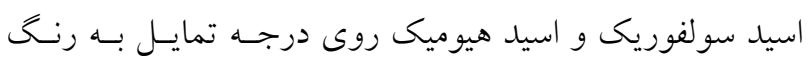

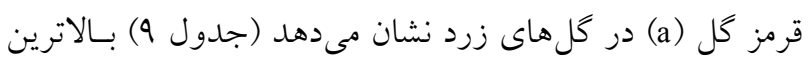

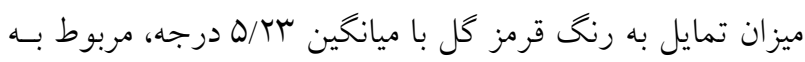

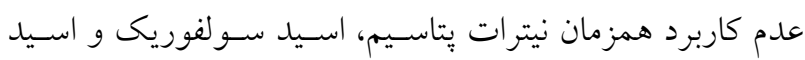

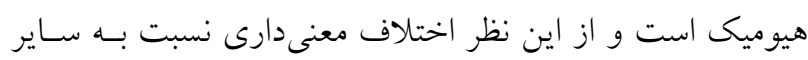

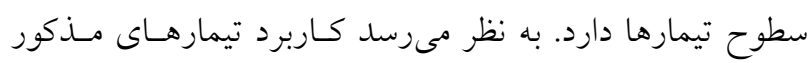

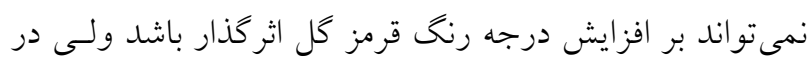

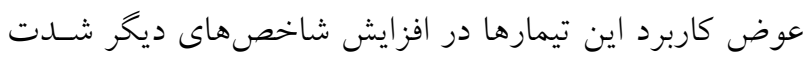

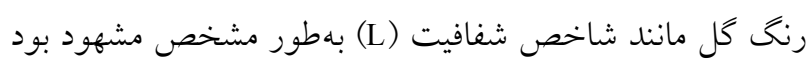

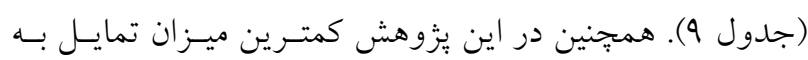

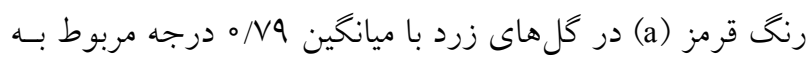

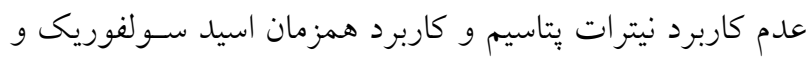

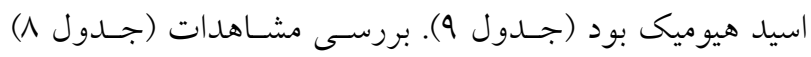

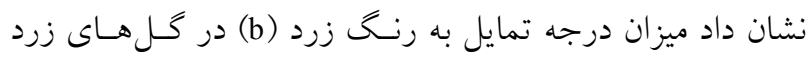

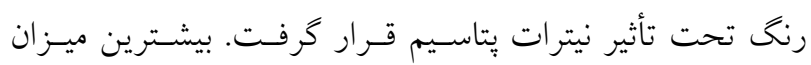

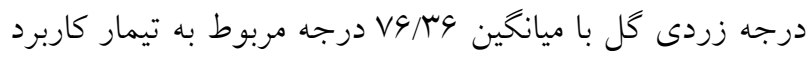

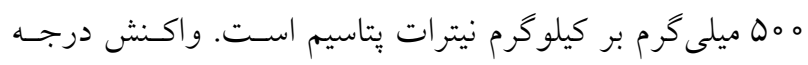

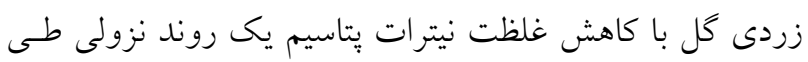

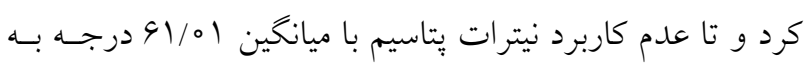
حداقل ميزان خود رسيد. نتايج حساكى از آن اسـت كـهـ كـاربرد

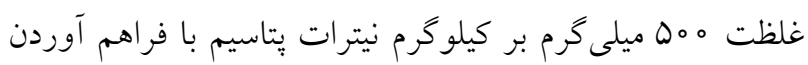

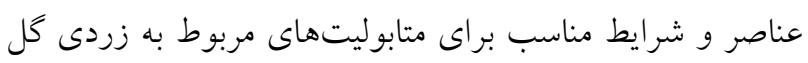
توانسته است بر شدت رنخ زردى كل مؤثر باشد.

\section{كيفيت رنغ گل نارنجى}

با مشاهده نتايج (جدول ه) مشخص مىشود درجه شفافيت (L)

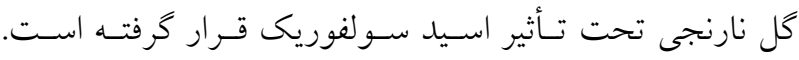

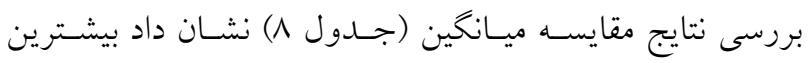

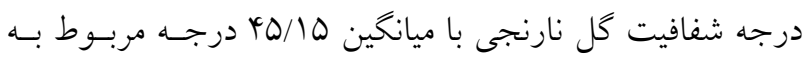

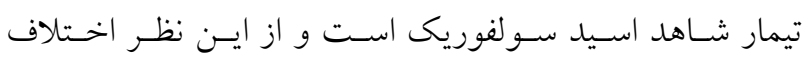
معنى دارى با كاربرد تيمار مذكور نشان مىدهد. به نظر مىرسيـ 


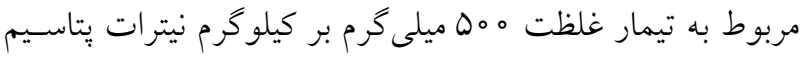

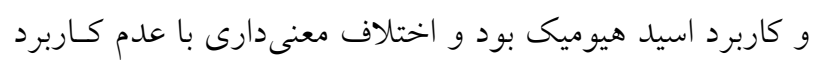

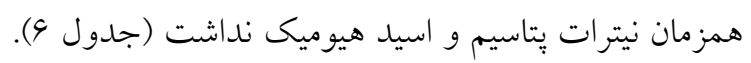

$$
\begin{aligned}
& \text { نتيجه گيرى }
\end{aligned}
$$

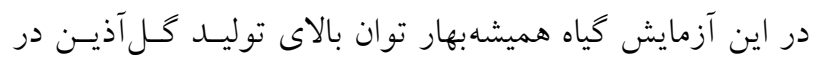

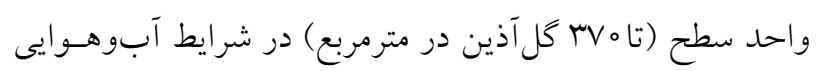

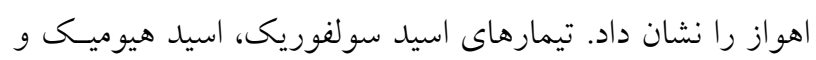

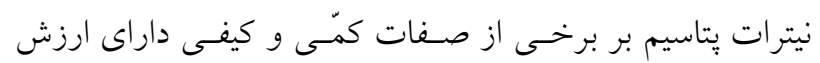

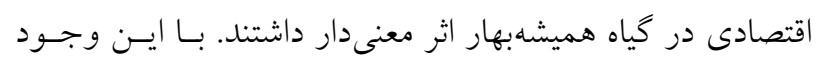

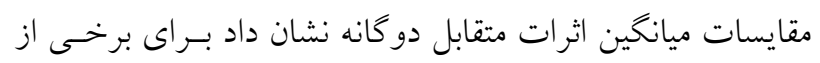

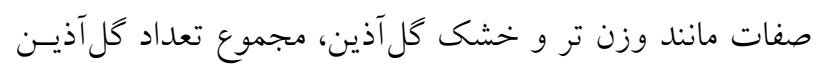

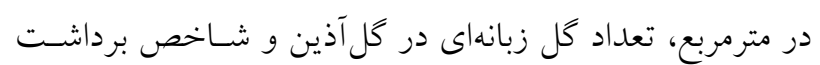

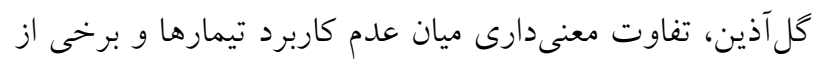

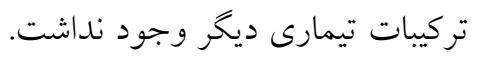

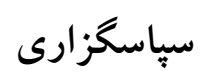

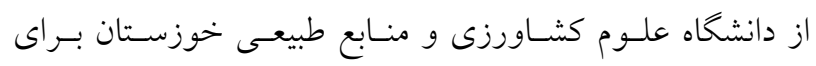

$$
\begin{aligned}
& \text { همكارى در اجراى اين بُزوهش تشكر و قدردانى مى نشود. }
\end{aligned}
$$

\section{منابع مورد استفاده}

1. Akihisa, T., K. Yasukawa, H. Oinuma, Y. Kasahara, S. Yamanouchi and M.Takido. 1996. Triterpene alcohols from the flowers of compositae and their anti-inflammatory effects. Phytochemistry 43: 1255-1260.

2. Arnon, D. I .1975. Physiological Principles of dry land crop production. pp. 3-14, In: U. S. Gupta (Ed.), Physiological Aspects of Dry Land Farming. Oxford and IBH Press. New Delhi.

3. Asgary, M., D. Habib and GH. Naderi. 2011. Effect of vermi compost, plant growth promoting Rhizobacteria and humic acid on growth factores of Mentha piperita L., in Central Province. Iranian Journal of Agronomy and Plant Breeding 7(4): 41-54. (In Farsi).

4. Berova, M., G. Karanatsidis, K. Sapundzhieva and V. Nikolova. 2010. Effect of organic fertilization on growth and yield of pepper plants (Capsicum annuum L.). Folia Horticulturae 22(1): 3-7.

5. Bisset, N. J. 1994. Herbal Drugs and Phytopharmaceuticals. Medpharm, Stuttgart and CRC, Bota Raton, Ann Arbor, London and Tokyo.

6. Boyhan G. E. 2008. Sulfur, its role in onion production and related alliums. pp. 183-196. In: J. Jez (Ed.). Sulfur: A Missing Link between Soils, Crops and Nutrition. Crop Science Society of America, American Society of Agronomy, Soil Science Society of America, Madison.

7. Chen, Y., M. Y. Xie and X. F. Gong. 2007. Microwave-assisted extraction used for the isolation of total triterpenoid saponins from Ganoderma atrum. Journal of Food Engineering 81: 162-170.

8. D'Angelo, G. H., E. B. Postulka and L. Ferrar. 2005. Infrequent and intense defoliation benefits dry-matter 
accumulation and persistence of clipped Arrhenatherum elatius. Grass and Forage Science 60(1): 17-24.

9. Droux, M. 2004. Sulfur assimilation and the role of sulfur in plant metabolism: A survey. Bayer Crop Science 79(3): 331-48.

10. Francis C. A., C. B. Flora and L. D. King.1990. Sustainable Agriculture in Temperate Zones. John Wiley and Sons, Incorporated. New York.

11. Golzadeh H., A. Mehrafarin, H. Naghdi Badi, F. Fazeli, A. Qaderi and N. Zarinpanjeh. 2012. Effect of biostimulators compounds on quantitative and qualitative yield of german chamomile (Matricaria recutita L.). Journal of Medicinal Plants 1(41): 195-207. (In Farsi).

12. Guinot, P., A. Gargadenne, G. Valette, A. Fruchier and C. Andary. 2008. Primary flavonoids in Marigold dye: extraction, structure and involvement in the dyeing process. Phytochemical Analysis 19(1): 46-51.

13. Halliwell, B., R. Aeschbach, J. Loliger and O. I. Aruoma. 1995. The characterization of antioxidants. Food and Chemical Toxicology 33(7): 601-617.

14. Haq, A., M. A. Pervez, F. M. Tahir and M. Ahmad. 1999. Effect of nitrogen, phosphorus and potassium on vegetative and reproductive growth of Rose (Rosa centifolia). International Journal of Agriculture and Biology 1(1-2): 27-29.

15. Hayes, M. and C. E. Clap. 2001. Humic substances: consideration of composition, aspect of structure and environment influences. Soil Science 166: 723-737.

16. Jabeen, N. and R. Ahmad. 2011. Foliar application of Potassium Nitrate Affects the Growth and Nitrate Reductase Activity in Sunflower and Safflower leaves under salinity. Notulae Botanicae Horti Agrobotanici Cluj-Napoca 39(2): 172-178.

17. Karimi, H., E. Tafazoli and N. Karimian. 2002. Effects of iron and sulfuric acid on vegetative and reproductive characteristics of strawberry (Fragaria ananassa Duch.) in calcareous soil. Iranian Journal of Horticultural Science and Technology 3: 29-38. (In Farsi).

18. Kazemi, M. 2013. Effect of foliar application with potassium nitrate and methyl jasmonate on growth and fruit quality of cucumber. Bulletin of Environment, Pharmacology and Life Science 2(11): 7-10.

19. Khodzhaeva M. A. and M. T. Turakhozhaev. 1993. Carbohydrates of calendula officinalis. Chemistry of Natural Compounds 29: 533-534.

20. Khosravi M. T., A. Mehrafarin, H. A. Naghdibadi, R. Hajiaghaee and E. Khosravi. 2011. Effect of methanol and ethanol application on yield of Echinacea purpurea L. in Karaj region. Journal of Herbal Drugs 2(2): 121-128. (In Farsi).

21. Kumaran, A. and R. J. Karunakaran, 2006. Antioxidant and free radical scavenging activity of an aqueous extract of Coleus aromaticus. Food Chemistry 97: 109-114.

22. Maie Mohsen, M. A. and H. Ismail. 2016. Response of calendula officinalis L. which grown in saline soil to plant growth promoters and some organic substances. International Journal of PharmTech Research 9(4): 153-172.

23. Malakouti, M. J. and M. Homaee. 2005. Soil Fertility of Arid and Semi-Arid Regions "Difficulties and Solutions". $2^{\text {nd }}$, ed. Tarbiat Modarres University Press, Tehran. (In Farsi).

24. Mallanagouda, B. 1995. Effects of N.P.K and fym on growth parameters of onion, garlic and coriander. Journal of Medic and Aromatic Plant Science 4: 916-918.

25. Meda, A., C. E. Lamien, M. Romito, J. Millogo and O. G. Nacoulma. 2005. Determination of the total phenolic, flavonoid and proline contents in Burkina Fasan honey, as well as their radical scavenging activity. Food Chemistry 91(3): 571-577.

26. Patrick, K. F. M., S. Kumar, P. A. D. Edwardson and J. J. Hutchinson. 1996. Induction of vascularization by an aqueous extract of the flowers of Calendula officinalis L. the European marigold. Phytomedicine 3(1): 11-18.

27. Raal, A., K. Kirsipuu, R. Must and S. Tenno. 2009. Content of total carotenoids in Calendula officinalis L. from different countries cultivated in Estonia. Natural Product Communications 4(1): 35-38.

28. Rainha, N., E. Lima, J. Baptista and C. Rodrigues. 2011. Antioxidant properties, total phenolic, total carotenoid and chlorophyll content of anatomical parts of Hypericum foliosum. Journal of Medicinal Plant Research 5(10): 19301940.

29. Rajendran, L., G. A. Ravishankar, L. V. Venkataraman and K. R. Prathiba. 1992. Anthocyanin production in callus cultures of Daucus carota as influenced by nutrient stress and osmoticum. Biotechnology Letters 14(8): 707-712.

30. Reuveni, M., D. Evenor, B. Artzi, A. Perl and Y. Erner. 2001. Decrease in vacuolar pH during petunia flower opening is reflected in the activity of tonoplast H+-ATPase. Journal of Plant Physiology 158(8): 991-998.

31. Salardini, A. and M. Mojtahedi. 2003. Principles of Plant Nutrition. Volume One. Tehran University Press. Tehran. (In Farsi).

32. Sakr, W. R. A. 2017. Chemical and biological fertilization of Calendula officinalis plant grown in sandy Soil. Journal of Horticultural Science \& Ornamental Plants 9(1): 17-27.

33. Shu, W. S., Z. H. Ye, C. Y. Lan, Z. Q. Zhang and M. H. Wong. 2001. Acidification of lead/zinc mine tailings and its effect on heavy metal mobility. Environment International 26: 389-394. 
34. Turgut, C., P. M. Katie and T. J. Curight. 2004. The effect of EDTA and citric acid on phytoremediation of Cd, Cr, and Ni from soil using Helianthus annuus. Environmental Pollution 131(1):147-154.

35. Ukiya, M., T. Akihisa, K. Yasukawa, H. Tokuda, T. Suzuki and Y. Kimura. 2006. Anti-inflammatory, anti-tumorpromoting and cytotoxic activities of constituents of marigold (Calendula officinalis) flowers. Journal of Natural Products 69(12): 1692-1696.

36. Vaseghi, S., M. Afyuni, H. Shariatmadari and M. Mobli. 2005. Effect of sewage sludge on some macronutrients concentration and soil chemical properties. Journal of Water and Wastewater 16:15-22. (In Farsi)

37. Walker D. J., R. Clemente and M. P. Bernal. 2004. Contrasting effects of manure and compost on soil pH, heavy metal availability and growth of Chenopodium album L. in a soil contaminated by pyretic mine wast. Chemosphere 57: $215-224$.

38. Wang Y. T .2007. Potassium nutrition effects on phalaenopsis growth and flowering. Horticultural Science 42(7): 1563-1567.

39. Yam K. L. and S. E. Papadakis. 2004. A simple digital imaging method for measuring and analyzing color of food surfaces. Journal of Food Engineering 61(1):137-142. 


\title{
Effect of Sulfuric Acid, Humic Acid and Potassium Nitrate Foliar Spraying on Petal Color Quality, Antioxidant Activity, Carotenoids and Flower Yield in Marigold (Calendula officinalis L.)
}

\author{
P. Nourolahi' ${ }^{1}$, A. Abdali Mashhadi2*, A. Koochekzadeh ${ }^{2}$ and M. H. Gharineh ${ }^{2}$
}

(Received: April 23-2018; Accepted: January 5-2019)

\begin{abstract}
In order to investigate the effects of sulfuric acid, humic acid and potassium nitrate foliar spraying on quantitative and qualitative of marigold a field trial was conducted in Ramin Agriculture and Natural Resources University of Khuzestan, Iran in 2015-2016. This study was carried out using a split factorial experiment in a randomized complete block design with four replications. Treatments included potassium nitrate $\left(\mathrm{N}_{1}=\right.$ no application, $\mathrm{N}_{2}=250 \mathrm{ppm}$ and $\mathrm{N}_{3}=$ $500 \mathrm{ppm})$ as the main factor, sulfuric acid $\left(\mathrm{S}_{1}=\right.$ no application and $\left.\mathrm{S}_{2}=5 \mathrm{~L} / \mathrm{ha}\right)$ and humic acid $\left(\mathrm{H}_{1}=\right.$ no application and $\mathrm{H}_{2}=16 \mathrm{~kg} / \mathrm{ha}$ ) as the second factor. Studied traits included capitol diameter, number of ray flowers in inflorescences, total number of inflorescences per $\mathrm{m}^{2}$, fresh and dry weight of inflorescences, harvest index, petal carotenoid concentrations, antioxidant activity and petal color quality ( $\mathrm{L}^{*} \mathrm{a} * \mathrm{~b}$ parameters). The highest inflorescence dry weight $\left(53 \mathrm{~g} \mathrm{~m}^{-2}\right)$, fresh and dry weight of inflorescences $\left(380 \mathrm{~g} \mathrm{~m}^{-2}\right)$, total number of inflorescences per $\mathrm{m}^{2}$ (372), number of ray flowers in inflorescences (58) and harvest index (14\%) were detected in $\mathrm{N}_{2} \mathrm{~S}_{1}, \mathrm{~N}_{2} \mathrm{~S}_{2}, \mathrm{~N}_{2} \mathrm{~S}_{2}, \mathrm{~N}_{2} \mathrm{~S}_{1}$ and $\mathrm{N}_{1} \mathrm{H}_{2}$, respectively. The least antioxidant activity $\left(0.048 \mathrm{mg} \mathrm{ml}^{-1}\right)$ was obtained in $\mathrm{S}_{1} \mathrm{H}_{2}$. The highest a (5.23) and $\mathrm{L}(61.64)$ color parameters for yellow flowers and $b(84.44)$ color parameter for orange flowers were found in $\mathrm{N}_{1} \mathrm{~S}_{1} \mathrm{H}_{1}, \mathrm{~N}_{3} \mathrm{~S}_{2} \mathrm{H}_{2}$ and $\mathrm{N}_{2} \mathrm{H}_{2}$, respectively. In general, the best treatments for the two important traits of inflorescence dry matter yield and number of inflorescences per square meter were $\mathrm{N}_{2} \mathrm{~S}_{1}$ and $\mathrm{N}_{2} \mathrm{~S}_{2}$, respectively.
\end{abstract}

Keywords Chroma meter, $\mathrm{L}^{*} \mathrm{a}$ b, Medicinal plant, Ray flowers

1, 2. MSc. Graduated Student and Associate Professors, Respectively, Department of Plant Production and Genetics, Faculty of Agriculture, Agricultural Sciences and Natural Resources University of Khuzestan, Mollasani, Khuzestan, Iran.

*: Corresponding Author, Email: alirezaabdali@ramin.ac.ir 